\title{
A Preliminary Study of the Virome of the South American Free-Tailed Bats (Tadarida brasiliensis) and Identification of Two Novel Mammalian Viruses
}

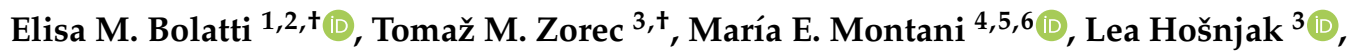 \\ Diego Chouhy ${ }^{1,2}$, Gastón Viarengo ${ }^{1}$ (D) Pablo E. Casal ${ }^{2} \mathbb{D}$, Rubén M. Barquez ${ }^{5,6} \mathbb{D}^{\text {, }}$ \\ Mario Poljak ${ }^{3, *(D)}$ and Adriana A. Giri 1,2,*(D) \\ 1 Grupo Virología Humana, Instituto de Biología Molecular y Celular de Rosario (CONICET), Suipacha 590, \\ Rosario 2000, Argentina; bolatti@ibr-conicet.gov.ar (E.M.B.); chouhy@ibr-conicet.gov.ar (D.C.); \\ viarengo@ibr-conicet.gov.ar (G.V.) \\ 2 Área Virología, Facultad de Ciencias Bioquímicas y Farmacéuticas, Universidad Nacional de Rosario, \\ Suipacha 531, Rosario 2000, Argentina; pablocasal380@gmail.com \\ 3 Institute of Microbiology and Immunology, Faculty of Medicine, University of Ljubljana, Zaloška 4, \\ SI-1000 Ljubljana, Slovenia; Tomaz-Mark.Zorec@mf.uni-lj.si (T.M.Z.); lea.hosnjak@mf.uni-lj.si (L.H.) \\ 4 Museo Provincial de Ciencias Naturales "Dr. Ángel Gallardo", San Lorenzo 1949, Rosario 2000, Argentina; \\ euge_montani22@hotmail.com \\ 5 Programa de Conservación de los Murciélagos de Argentina, Miguel Lillo 251, \\ San Miguel de Tucumán 4000, Argentina; rubenbarquez@gmail.com \\ 6 Programa de Investigaciones de Biodiversidad Argentina, Facultad de Ciencias Naturales e Instituto Miguel \\ Lillo, Universidad Nacional de Tucumán, Miguel Lillo 205, San Miguel de Tucumán 4000, Argentina \\ * Correspondence: Mario.poljak@mf.uni-lj.si (M.P.); giri@ibr-conicet.gov.ar (A.A.G.); \\ Tel.: +386-1-543-7454 (M.P.); +54-341-435-0661 (ext. 116) (A.A.G.); Fax: +54-341-439-0465 (A.A.G.) \\ + These authors contributed equally.
}

Received: 10 March 2020; Accepted: 3 April 2020; Published: 9 April 2020

\begin{abstract}
Bats provide important ecosystem services as pollinators, seed dispersers, and/or insect controllers, but they have also been found harboring different viruses with zoonotic potential. Virome studies in bats distributed in Asia, Africa, Europe, and North America have increased dramatically over the past decade, whereas information on viruses infecting South American species is scarce. We explored the virome of Tadarida brasiliensis, an insectivorous New World bat species inhabiting a maternity colony in Rosario (Argentina), by a metagenomic approach. The analysis of five pooled oral/anal swab samples indicated the presence of 43 different taxonomic viral families infecting a wide range of hosts. By conventional nucleic acid detection techniques and/or bioinformatics approaches, the genomes of two novel viruses were completely covered clustering into the Papillomaviridae (Tadarida brasiliensis papillomavirus type 1, TbraPV1) and Genomoviridae (Tadarida brasiliensis gemykibivirus 1, TbGkyV1) families. TbraPV1 is the first papillomavirus type identified in this host and the prototype of a novel genus. TbGkyV1 is the first genomovirus reported in New World bats and constitutes a new species within the genus Gemykibivirus. Our findings extend the knowledge about oral/anal viromes of a South American bat species and contribute to understand the evolution and genetic diversity of the novel characterized viruses.
\end{abstract}

Keywords: Tadarida brasiliensis; metagenomics; Papillomaviridae; TbraPV1; Genomoviridae; TbGkyV1

\section{Introduction}

Bats belong to the order Chiroptera, which is the second-largest mammalian group, comprising 21 families and 1411 species distributed globally, with the exception of polar areas [1,2]. Approximately 
$25 \%$ of the world's bat species are endangered, causing concerns about the negative conservation impact and its influence on the ecosystem services these bats provide, such as arthropod regulation, seed dispersal, and pollination [1,3]. On the other hand, certain specific aspects of bats-including their relatively long lifespan in relation to their body size [4], the reliance of some species on prolonged torpor [5], and flight-may make them suitable for hosting a wide variety of viruses [6], including zoonotic viruses highly pathogenic to humans [6], such as severe acute respiratory syndrome (SARS)-related coronavirus, Ebola virus, Nipah virus, and Hendra virus [7-10]. Nevertheless, little is known about their own pathogens [3]. In addition, the gregarious behavior of many bat species, such as free-tailed bats Tadarida brasiliensis (I. Geoffroy Saint-Hilaire, 1824), may facilitate rapid transmission of pathogens between bats and other species [6]. T. brasiliensis is the most abundant migratory and cosmopolitan species of the New World bats, widespread throughout the Americas [11-13] and protected by international agreements [14].

Using next-generation sequencing (NGS) technologies, an enormous variety of viral species and genotypes $[15,16]$ have been identified in the tissues and feces of bats mainly inhabiting Asia [17,18], Africa $[19,20]$, Europe [21,22], and North America [23,24]. On the other hand, the viromes of bats from South America remain understudied $[25,26]$. For example, the identification of viruses infecting T. brasiliensis is principally limited to detection of specific viral families, such as rabies lyssavirus [27], alphacoronaviruses [28], polyomaviruses [29], circoviruses [30], and anelloviruses [31].

In order to contribute to the preservation of T. brasiliensis and to evaluate its possible role as a pathogen reservoir, greater efforts directed at identifying the viruses present in this species are needed. In this study we report a detailed description of two novel complete genome sequences, one describing a new papillomavirus genus and the other representing a novel variant of an existing gemykibivirus species. In addition, we report a preliminary overview of the T. brasiliensis virome composition. Altogether, our findings add to the knowledge of viral diversity in a South American bat species, providing insights for understanding their role as reservoirs, as well as their own pathogens, which may have consequences for the animals' health.

\section{Materials and Methods}

\subsection{Study Area, Sample Collection, and Ethics Statement}

The bat colony investigated occupies the attic of the Law School building at the Universidad Nacional de Rosario in downtown Rosario, Argentina ( $32^{\circ} 56^{\prime} 36.76^{\prime \prime} \mathrm{S} 60^{\circ} 39^{\prime} 02.09^{\prime \prime} \mathrm{W}$ ) [32]. In this place, T. brasiliensis (Molossidae) establishes a maternity colony every year that can reach about 30,000 individuals during the maternity season (November to March), after which they migrate [32,33].

A total of 98 swab samples ( 49 oral and 49 anal) were collected from 49 adult female specimens inhabiting this colony from December 2015 to February 2016. Briefly, bats were manually captured from the walls and held in individual cotton bags for determination of their species based on anatomical and morphological characters, reproductive condition, and age [33].

The oral cavity and anal regions of each individual were sampled using individual sterile cottontipped swabs (Deltalab, Barcelona, Spain), rolled back and forth (10 times), suspended in $200 \mu \mathrm{L}$ of saline solution $(\mathrm{NaCl} 0.9 \%)$, and stored at $4{ }^{\circ} \mathrm{C}$ until further processing. The bats were rehydrated and released.

During this study, every effort was made to minimize interference with and suffering of the animals; no breeding or pregnant females were captured, and no animals were sacrificed. Sample collection was conducted by trained professionals as approved by the Ministry of Environment of the Argentinian Santa Fe Province (file 021010016257-1) and Facultad de Ciencias Bioquímicas y Farmacéuticas (Universidad Nacional de Rosario) animal ethics committee (file 6060/243, 20 March 2015).

\subsection{Sample Processing and Viral DNA Enrichment}

Samples were processed according to previously published protocols that have been successfully applied for identification of papillomavirus (PV) in human skin swab samples [34-36]. Briefly, the cells 
were centrifuged at $13,000 \times g$ for $5 \mathrm{~min}$ and the pellets were resuspended in $100 \mu \mathrm{L}$ TE buffer (Qiagen, Hilden, Germany) containing $100 \mu \mathrm{g}$ of proteinase K (Qiagen), and incubated overnight at $55^{\circ} \mathrm{C}$. Following proteinase $\mathrm{K}$ inactivation $\left(95^{\circ} \mathrm{C}\right.$ for $\left.10 \mathrm{~min}\right)$, the lysates were stored at $-20^{\circ} \mathrm{C}$. Subsequently, the obtained samples were tested for the presence of PV DNA using improved versions of FAP $[37,38]$ and CUT PCRs [35], as described previously [36,39]. Circular DNA molecules in lysates of five selected PV-positive samples (four anal and one oral swab) were enriched using rolling-circle amplification (RCA) with the illustra TempliPhi 100 Amplification Kit (GE Healthcare, Chicago, IL, USA) [40-42].

\subsection{Next-Generation Sequencing (NGS), Read Quality Control, and Sequence Filtering}

The pool of RCA-enriched samples was sequenced on an Illumina Hiseq 4000 instrument at the sequencing facility of GATC Biotech (Ebersberg, Germany). Sequencing libraries were prepared using the GATC automatic library preparation approach, and the sequencing reads were sequestered in the format of $2 \times 150 \mathrm{bp}$. Reads were subjected to quality trimming and filtering using the bbduk program (BBTools v38.42). End trimming was performed on the first and last 15 bases of each read, clipping bases with PHRED scores below 15. Trimmed reads shorter than $120 \mathrm{bp}$ and with an average PHRED score below 20 were discarded.

The read pairs contained in the metagenomic sample, which shared k-mers, sliding-window subsequences of $27 \mathrm{nt}$, with the sequencing datasets of samples (six in total) that were processed and analyzed in the same sequencing batch, were discarded using the bbduk program (referred to as laboratory-batch background screen in Figure 1). The primary purpose of this step was to conservatively limit the possibility of falsely identifying viral taxa that did not originate from the bat metagenomics sample and that could have been introduced by aerosol during sample processing or index hopping during sequencing.

In order to limit the content of bacterial reads, the metagenomic dataset was mapped to the bacterial reference-index files (obtained 6 November 2017, from ftp://ftp.ccb.jhu.edu/pub/infphilo/ centrifuge/data/p_compressed.tar.gz) using the centrifuge sequence classification system (Centrifuge version 1.0.3-beta) [43]. Reads not mapping to any bacterial taxon were used in further metagenomic analyses (unless stated otherwise).

\subsection{Metagenomic Analysis Workflow}

Two types of metagenomic characterization workflows were used: (1) taxonomic classification of NGS read pairs and (2) taxonomic classification of contigs assembled de novo from NGS read pairs. In both cases, the centrifuge metagenomic classification system with the reference nucleic sequence index files, obtained from ftp://ftp.ccb.jhu.edu/pub/infphilo/centrifuge/data/p_compressed $+\mathrm{h}+\mathrm{v}$.tar.gz (version 12 June 2016, downloaded 6 November 2017), was used to obtain the final taxonomic calls (default parameter settings). Taxonomic classification of sequences was further summarized to the taxonomic level of family using pavian [44].

De novo assembly was performed with two different De Brujin graph assembly tools: SPAdes (v3.11) [45] and Unicycler (obtained from github: 27 October 2017; github commit: 220d5daebc8267d3 7378f191e14acb5c5a1ff757), adapting various parameter settings. Altogether, six different metagenomic de novo assemblies were constructed, using settings specified in Table S1. All contigs assembled de novo by any of the six approaches exhibiting a minimum length of $500 \mathrm{nt}$ were collected and subjected to taxonomic classification (workflow 2).

\subsection{Characterization of Novel Viral Genome Sequences and Phylogenetic Analysis}

The circularity of the complete genome assemblies was determined by matching the sequence stretches (minimum match length $50 \mathrm{nt}$ ) at their $5^{\prime}$ and $3^{\prime}$ ends. Coverage statistics of the novel complete viral genome sequences were obtained by remapping the trimmed read dataset to the constructed genome assemblies using bowtie2 (v2.2.6) [46]. 


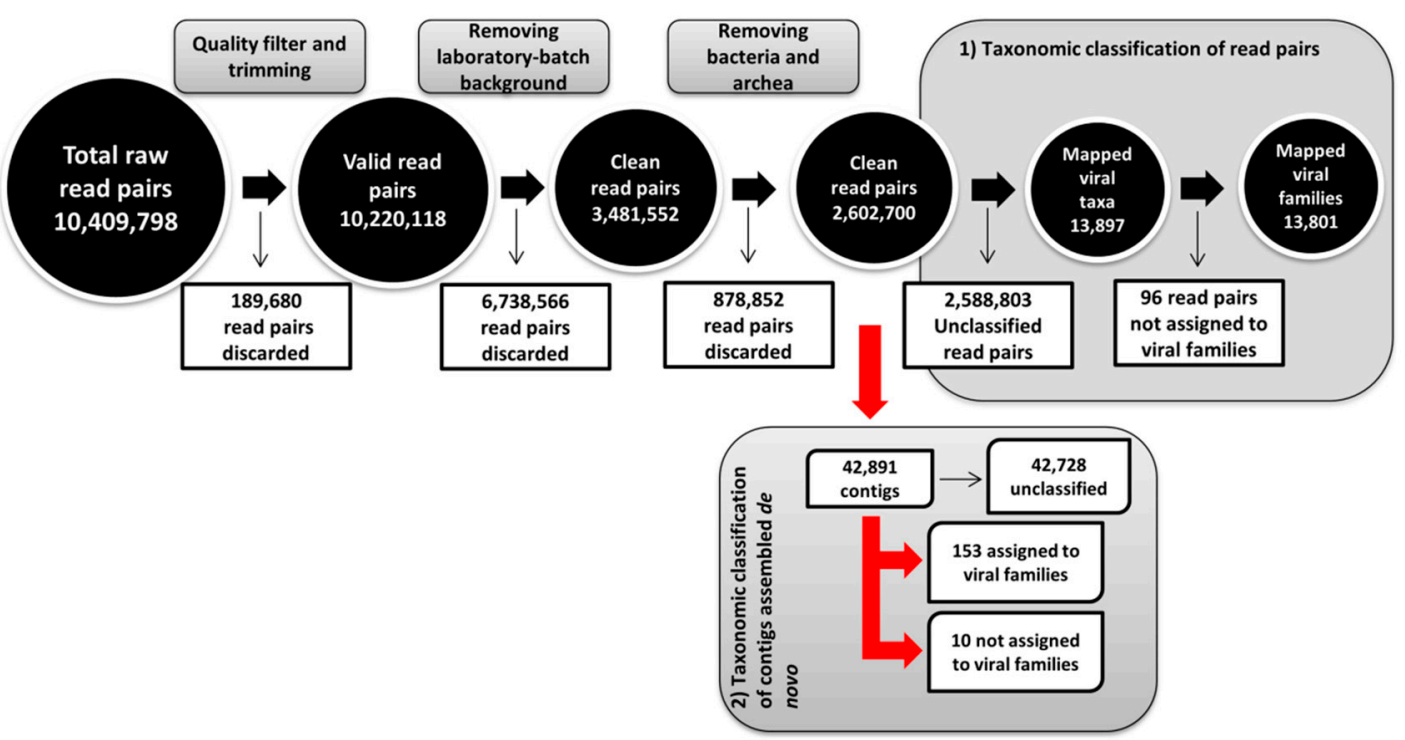

Figure 1. Next-generation sequencing (NGS) data analysis workflow. Metagenomic characterization workflow and taxonomic classification strategies of Illumina pair reads (1) and contigs assembled de novo (2). Pair reads quality filtering and trimming were performed with the bbduk program (BBTools v38.42). The centrifuge metagenomics classification system was used for the taxonomic classification of pair reads and contigs (Centrifuge version 1.0.3-beta) [43]. De novo assembly was performed using SPAdes v3.11 [45] and Unicycler.

Sequences of the E1,E2, L2, and L1 genes of 376 reference PV genomes, downloaded from PaVe (http://pave.niaid.nih.gov/ on 13 March 2019), and the corresponding genes from the novel PV, Tadarida brasiliensis papillomavirus type 1 (TbraPV1), were used in the phylogenetic analysis. Additional information on nucleotide sequences (GenBank accession number and virus name abbreviations) used in these analyses is summarized in Table S2. The E1E2L2L1 concatenation was constructed by first obtaining the amino acid-guided multiple sequence alignments of each gene. Multiple sequence alignments were obtained using Muscle (v3.8.31) [47]. As suggested by Bernard et al. (2010) [48], the multiple sequence alignments used for phylogenetic analysis of TbraPV1 were guided by the amino acid alignments and the PV identity calculation was based on patristic distance measurements, as determined by SeaView [49]. Phylogenetic clustering was conducted using IQ-TREE [50]. The most appropriate substitution models were determined using ModelFinder [51], according to the Bayesian information criterion. Branch support values were calculated using UF bootstrap (1000 replicates) [52], SH-aLRT (1000 replicates), and aBayes tests [53].

Phylogenetic analysis of Genomoviridae was conducted using a reference dataset of 166 complete genome nucleotide sequences and 166 Rep protein sequences downloaded from NCBI GenBank (19 March 2019). The complete genome sequences were rotated to all begin in the start codon of the Rep gene using circulator (version: GitHub commit a4befb8c9dbbcd4b3ad1899a95aa3e689d58b638) [54], and the two subunits of the Rep gene were concatenated into a single protein sequence in which the GenBank record indicated them as parts of different genes/coding sequences. Pairwise sequence identity values used for taxonomic classification of Tadarida brasiliensis gemykibivirus 1 (TbGkyV1) were obtained using Sequence Demarcation Toolkit (SDT v1.0) [55]. In this scope, the pairwise sequence alignments were produced using Muscle (v3.8.1) [47]. Phylogenetic trees were rendered using FigTree (v1.4.4) (http://tree.bio.ed.ac.uk/software/figtree/), and sequence identity histograms were visualized using gnuplot (v1.5).

Open reading frames (ORFs) of novel viral genome sequences were marked using ORFfinder (NCBI); the manual annotation process of the ORFs was guided by the use of NCBI BLASTp, and the identification of viral-family specific sequence motifs was performed using regular expressions with 
the linux grep utility (v2.16). Members of Papillomaviridae and Genomoviridae identified in bat species so far are summarized in Table S3.

\subsection{Complete Papillomavirus Genome Confirmation}

The complete genome sequence of the novel PV type (TbraPV1) was obtained by generating four overlapping amplicons in different PCR reactions, using 1 X PCR buffer, $3.5 \mathrm{mM}$ of $\mathrm{MgCl}_{2}, 200 \mu \mathrm{M}$ of each dNTP (Thermo Fisher, Walthem, MA, USA), 1.25 U of GoTaq HotStart polymerase (Promega, Madison, WI, USA), and $0.8 \mu \mathrm{M}$ of each of the primers (TbraPV1-1F $5^{\prime}$-cagggtattcagggtgtttctcc- $3^{\prime}$ and TbraPV1-1R 5' -aatgtttctaatctgcaacc-3'; TbraPV1-2F 5'-gtgcgcggcgacttctcatactta-3' and TbraPV1-2R 5' tcagcctcattgtcctcatcattg-3'; TbraPV1-3F $5^{\prime}$-tgggcttgaaacctggacactaca-3' and TbraPV1-3R $5^{\prime}$-atgcccgggaa tatggatgga-3'; TbraPV1-4F 5'-ggcctgcaagaccacctac-3' and TbraPV1-4R 5'-gggggcatctgacctgtta-3'). Cycling conditions for the four reactions were the same and were performed as follows: initial denaturation at $95{ }^{\circ} \mathrm{C}$ for $2 \mathrm{~min}$, followed by 45 cycles of $40 \mathrm{~s}$ at $94{ }^{\circ} \mathrm{C}, 40 \mathrm{~s}$ at $50{ }^{\circ} \mathrm{C}$, and $2 \mathrm{~min}$ at $72{ }^{\circ} \mathrm{C}$, with a final extension at $72{ }^{\circ} \mathrm{C}$ for $5 \mathrm{~min}$. The amplicons were resolved in a $1 \%$ agarose gel electrophoresis and the $\sim 2 \mathrm{~kb}$ fragments were gel purified, ligated into the pGem-T Easy Vector (Promega), and transformed into E. coli cells. Sanger sequencing was performed using sequencing facilities at Macrogen Inc. (Seoul, Korea). In August 2019, DNA clones and the corresponding nucleotide sequences were subsequently submitted to the Animal Papillomavirus Reference Center (http://www.animalpv.org/) for its confirmation and official designation.

\subsection{Nucleotide Sequence Accession Number}

The GenBank/EMBL/DDBJ accession numbers for the novel viruses reported in this paper are TbraPV1 (MN329804) and TbGkyV1 (MN329805). The relevant raw high throughput sequencing data obtained in this study was deposited at the NCBI Sequence Read Archives (SRA) with the following accession number: PRJNA615356. The contigs, obtained by de novo assembly as part of the metagenomic workflow (2), have also been made available for download (Supplementary Data S1).

\section{Results}

\subsection{Global Analysis of High-Throughput Sequencing Data}

NGS data analysis workflows and centrifuge-based taxonomic assignments of reads and contigs are depicted in Figure 1 and Table 1, respectively. Briefly, a total of 10,409,798 read pairs were sequestered from the RCA-enriched samples, and 10,220,118 of them passed the quality filtering and trimming procedures. Out of these, 6,738,566 read pairs were removed during the laboratory-batch background screen and an additional 878,852 read pairs were identified as originating from bacteria. The final metagenomic characterization was carried out using the remaining 2,602,700 read pairs (Figure 1). Metagenomic analysis revealed that only a small proportion of read pairs $(13,897$ read pairs; $0.534 \%)$ and de novo assembled contigs longer than $500 \mathrm{nt}(153$ out of total 42,$891 ; 0.357 \%)$ mapped to viral taxa.

Overall, a large number of phage-related sequences were detected $(77.3 \%$ of viral read pairs and $39.9 \%$ of viral contigs), likely representing the most abundant entities infecting bacteria present in the bat digestive system, which exhibited similarity mostly to the families Inoviridae, Siphoviridae, and Myoviridae (Table 1). The eukaryotic viral sequences (insect, invertebrate, plant, protist, and vertebrate viruses) could be summarized into a total of 35 viral families, 22 corresponding to viral families with DNA genomes, and 13 to families with RNA genomes.

Sequences of 10 different viral families infecting insects and crustaceans, mostly found related to the families Baculoviridae, Ascoviridae, Iridoviridae, and Nimaviridae, were detected $(0.900 \%$ of viral read pairs and $12.4 \%$ of assembled viral contigs). On the other hand, sequences related to viruses infecting plants (five viral families, $0.446 \%$ of viral read pairs, and $4.57 \%$ of viral contigs) were mostly associated with Phycodnaviridae or Potyviridae, whereas those related to viruses infecting protists (five viral families, $13.6 \%$ of viral read pairs, $0.654 \%$ of viral contigs) clustered predominantly in the family Mimiviridae. 
Table 1. Read pairs and contigs of virus families identified in anal and oral swab samples of Tadarida brasiliensis obtained by metagenomics using Illumina technology.

\begin{tabular}{|c|c|c|c|c|}
\hline Host & Family & No. of Read Pairs & No. of Contigs & Genome Type \\
\hline \multirow{8}{*}{ Bacteria, Archea } & Inoviridae & 9908 & 8 & ssDNA-C \\
\hline & Siphoviridae & 666 & 29 & dsDNA-C \\
\hline & Myoviridae & 120 & 18 & dsDNA-L \\
\hline & Podoviridae & 33 & 6 & dsDNA-L \\
\hline & Rudiviridae & 6 & 0 & dsDNA-L \\
\hline & Sphaerolipoviridae & 3 & 0 & dsDNA-L \\
\hline & Microviridae & 1 & 0 & ssDNA-C \\
\hline & Leviviridae & 1 & 0 & ssRNA-L \\
\hline \multirow[t]{5}{*}{ Total } & 8 & 10,738 & 61 & 7 DNA; 1 RNA \\
\hline & Baculoviridae & 34 & 7 & dsDNA-C \\
\hline & Ascoviridae & 34 & 0 & dsDNA-C \\
\hline & Iridoviridae & 29 & 6 & dsDNA-C \\
\hline & Nudiviridae & 15 & 0 & dsDNA-C \\
\hline \multirow{6}{*}{$\begin{array}{l}\text { Insects and other } \\
\text { invertebrates }\end{array}$} & Hytrosaviridae & 4 & 2 & ssDNA-C \\
\hline & Dicistroviridae & 3 & 0 & ssRNA-L \\
\hline & Polydnaviridae & 2 & 0 & dsDNA-C \\
\hline & Solinviviridae & 2 & 3 & ssRNA-L \\
\hline & Asfarviridae & 1 & 1 & dsDNA-L \\
\hline & Nimaviridae & 1 & 0 & dsDNA-C \\
\hline Total & 10 & 125 & 19 & 8 DNA; 2 RNA \\
\hline \multirow{5}{*}{ Plants } & Phycodnaviridae & 42 & 6 & dsDNA-C \\
\hline & Potyviridae & 10 & 0 & ssRNA-L \\
\hline & Geminiviridae & 8 & 0 & ssDNA-C \\
\hline & Caulimoviridae & 1 & 0 & dsDNA-RT-C \\
\hline & Tymoviridae & 1 & 1 & ssRNA-L \\
\hline Total & 5 & 62 & 7 & 3 DNA; 2 RNA \\
\hline \multirow{5}{*}{ Protists } & Mimiviridae & 1825 & 0 & dsDNA-L \\
\hline & Marseilleviridae & 65 & 1 & dsDNA-C \\
\hline & Narnaviridae & 1 & 0 & ssRNA-L \\
\hline & Totiviridae & 1 & 0 & dsRNA-L \\
\hline & Pithoviridae & 1 & 0 & dsDNA-C \\
\hline Total & 5 & 1893 & 1 & 3 DNA; 2 RNA \\
\hline \multirow{15}{*}{ Vertebrates } & Retroviridae & 461 & 22 & ssRNA-RT-L \\
\hline & Genomoviridae & 258 & 6 & ssDNA-C \\
\hline & Herpesviridae & 113 & 4 & dsDNA-L \\
\hline & Papillomaviridae & 90 & 14 & dsDNA-C \\
\hline & Poxviridae & 36 & 6 & dsDNA-L \\
\hline & Alloherpesviridae & 10 & 1 & dsDNA-L \\
\hline & Rhabdoviridae & 3 & 2 & ssRNA-L \\
\hline & Reoviridae & 3 & 0 & dsRNA-L \\
\hline & Astroviridae & 2 & 0 & ssRNA-L \\
\hline & Circoviridae & 2 & 0 & ssDNA-C \\
\hline & Adenoviridae & 1 & 0 & dsDNA-L \\
\hline & Polyomaviridae & 1 & 0 & dsDNA-C \\
\hline & Coronaviridae & 1 & 0 & ssRNA-L \\
\hline & Paramyxoviridae & 1 & 0 & ssRNA-L \\
\hline & Flaviviridae & 1 & 0 & ssRNA-L \\
\hline Total & 15 & 983 & 55 & 8 DNA; 7 RNA \\
\hline $\begin{array}{c}\text { Total sequences assigned to } \\
\text { viral families }\end{array}$ & 43 & 13,801 & 143 & 29 DNA; 14 RNA \\
\hline \multicolumn{2}{|c|}{ Viral sequences not assigned to families } & 96 & 10 & \\
\hline \multicolumn{2}{|c|}{ Total viral sequences } & 13,897 & 153 & \\
\hline
\end{tabular}

ss $=$ single strand, $\mathrm{ds}=$ double strand, $\mathrm{C}=$ circular $\mathrm{L}=$ linear.

Sequences classified as originating from vertebrates, predominantly mammalian viruses, were represented by $7.07 \%$ of viral read pairs and $35.9 \%$ of viral contigs. The principal viral families identified included Retroviridae, Genomoviridae, Herpesviridae, Papillomaviridae, and Poxviridae. The analysis also identified (although in low counts) viral sequences related to the family Alloherpesviridae, which infects 
fish and amphibians. Of note, the metagenomic analysis indicated that 205 out of 461 read pairs were assigned to the family Retroviridae (1.48\% of viral read pairs), and 22 assembled contigs (14.4\% of viral contigs; Table 1) exhibited resemblance to the nucleotide sequence of Desmodus rotundus endogenous retrovirus isolate 824 (Genbank accession number: NC_027117) [56]. However, a more detailed analysis of this sequence revealed the presence of two flanking regions at the $5^{\prime}$ and $3^{\prime}$ ends of approximately $1000 \mathrm{nt}$, which probably derived from the host genome (Desmodus rotundus). In fact, contigs and reads previously classified as Retroviridae in our study aligned with these flanking regions. This finding explained the initial misclassification and indicated that great care should be taken when using GenBank sequence data as reference material because a large portion of sequences and their respective annotations may not have been curated adequately.

Finally, a total of 96 read pairs and 10 assembled contigs were classified as similar to viruses unassigned to taxonomical families (Table S4).

\subsection{Identification of Novel Bat Viruses}

\subsubsection{Papillomaviridae}

The metagenomic analysis suggested that a total of 90 read pairs (workflow 1) and 14 contigs (workflow 2) could be attributed to PVs (Table 1). The longest contig obtained by assembly de novo covered the complete genome of TbraPV1, which was subsequently confirmed by conventional molecular methods (PCR, cloning, and Sanger sequencing; data not shown).

Remapping read pairs (quality-, background-, and bacteria-filtered read pairs) to the confirmed TbraPV1 genome sequence indicated a complete sequence length of 8151 nt, with a GC content of $46 \%$. The complete novel genome sequence was covered on average $252.6 \times$ by a total of 6935 read pairs (13,870 reads). Detailed analysis of the TbraPV1 viral genome (Table 2 and Figure 2A), showed a typical genomic organization of bat PVs, potentially encoding four early genes $(E 6, E 7, E 1$, and E2) and two late genes (L2 and L1) [57,58]. A putative E4 gene was found overlapping the E2 gene (Figure 2A), with its own start and stop codons, and the presence of E4-characteristic proline-rich stretches (12.7\%) with an important role in cell cycle arrest was found [59].
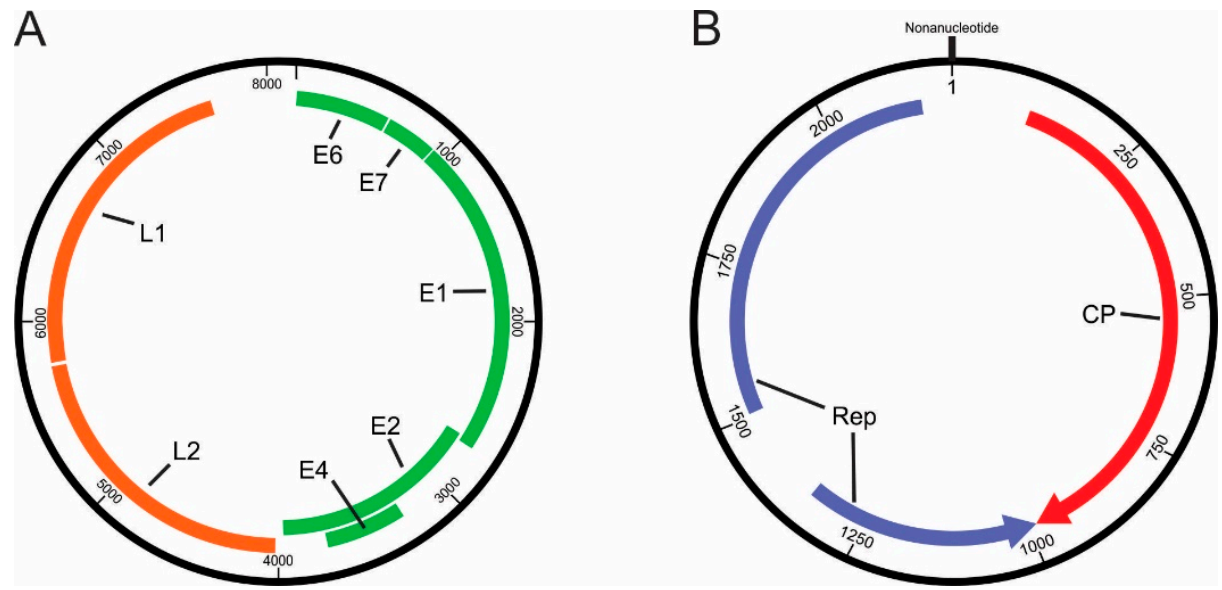

Figure 2. (A) Tadarida brasiliensis papillomavirus type 1 (TbraPV1) genome diagram indicating the positions of annotated PV genes. All genes are read from the direct strand. Genes encoding early and late proteins are depicted with green and orange lines, respectively. (B) Tadarida brasiliensis gemykibivirus 1 (TbGkyV1) genome diagram. Genes encoding the replication initiation protein (Rep) and the capsid protein $(\mathrm{CP})$ are shown with blue and red arrows, respectively. Note that the Rep gene is on the reverse-complemented strand. The position of the nonanucleotide (TATAAATAG) is also indicated.

The upstream regulatory region (URR) of TbraPV1 contained two typical TATA boxes, three putative E2 protein binding sites, an E1 protein binding site [60], and three putative polyadenilation 
sites for late gene transcripts (Table 2). Multiple potential binding sites for transcriptional regulatory factors, such as AP-1, NF-1, and SP-1, were also present within the URR (data not shown).

Table 2. Main genomic features and putative proteins of the novel Tadarida brasiliensis papillomavirus type 1 .

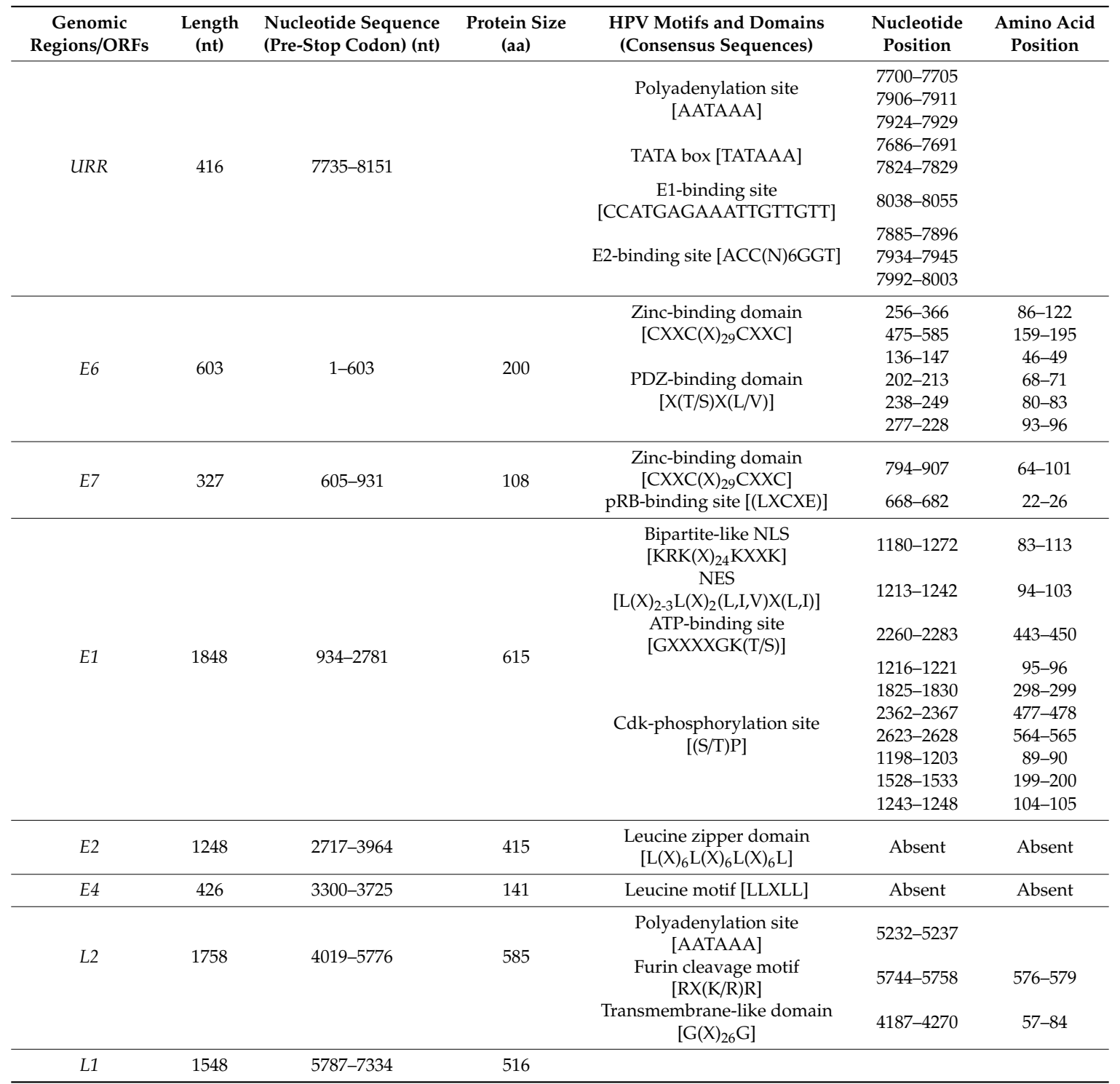

Typical domains were additionally identified in the putative viral proteins encoded by TbraPV1. The E6 protein contained two characteristic zinc-binding domains, separated by 36 amino acids [61], and four internal and likely not functional PDZ-binding motifs (RTNV, ISDL, SSIL, LSSL) [62]. The E7 protein contained a pRB-binding motif (LWCDE) [63] and a single zinc-binding domain (Table 2). Analysis of the E1 protein, the largest protein encoded by TbraPV1 (Table 2), showed the typical ATP-binding site of the ATP-dependent helicase (GPSNSGKS) [64], and several Cdk-phosphorylation and Cyclin-binding sites. A highly conserved bipartite-like nuclear localization signal (NLS) and a leucine-rich Crm1-dependant nuclear export signal (NES) (LSPVLEKVTI), which together allow shuttling of the E1 protein between the cell nucleus and the cytoplasm in most human PVs [65-67], were identified at the N-termini of the E1 protein. No conserved leucine zipper domain was present at the C-termini of the putative TbraPV1 E2 protein, in agreement with other bat PVs (EsPV2 and RfPV1) [58]. At the N-termini of the L2 protein, a highly conserved furine cleavage motif (RRKR), as well as a transmembrane-like domain (GTGGGGRGVPIGPRVATGRPGGPINSVG) [68], were identified. 
In addition, a canonical polyadenylation site, necessary for regulation of early viral transcripts [69], was also found in the TbraPV1 L2 gene (Table 2).

Phylogenetic analysis, based on 377 PV L1 gene nucleotide sequences, indicated peak sequence identities of TbraPV1 to HPV41 and RfPV1, which amounted to 61.5 and 60.6\%, respectively (Figure 3, charts A2 and A4). Maximum likelihood phylogenetic clustering of L1 sequences (Figure 4) suggested common ancestry of TbraPV1, EdPV1, and HPV41, and that TbraPV1 branched away prior to the delineation of EdPV1 and HPV41, with high SH-aLRT, aBayes, and UF bootstrap support values. Further phylogenetic analyses were conducted based on the concatenated alignments of 377 E1, E2, $L 2$, and $L 1$ gene nucleotide sequences, and they indicated a peak sequence identity of TbraPV1 to RfPV1 (54.1\%, Figure 3, charts A1 and A3), whereas the maximum likelihood phylogenetic clustering indicated analogous common ancestry to the concatenated PV genes (Figure 5), with high SH-aLRT, aBayes, and UF bootstrap support values.

\subsubsection{Genomoviridae}

The metagenomic analysis indicated the presence of several genomovirus-related read pairs and sequence contigs (Table 1), and the complete genome sequence (2196 nt) of TbGkyV1 was recovered using de novo assembly. Remapping to the TbGkyV1 genome sequence indicated a mean coverage of $59.4 \times$ by a total of 430 read pairs ( 860 paired reads +7 unpaired reads) and did not reveal any abnormalities that would indicate misassembly. Completeness of the circular genome sequence was determined by matching $5^{\prime}$ and $3^{\prime}$ ends, and the sequence was rotated to begin with the characteristic Genomoviridae nonanucleotide motif [70]. Three non-overlapping ORFs, with a minimum protein length of 120 aa, were found, exhibiting peak amino acid similarities to the Genomoviridae Rep and $\mathrm{CP} / \mathrm{Cap}$ proteins. The Rep protein of TbGkyV1 was encoded across two different Rep-encoding ORFs separated by an intron, representing a catalytic and a central protein domain (Figure 2B, Table 3), which is characteristic for replication-associated proteins encoded by single-stranded (CRESS) DNA viruses [71].

Table 3. Main genomic features and putative proteins of the novel Tadarida brasiliensis gemykibivirus 1.

\begin{tabular}{|c|c|c|c|c|c|c|c|}
\hline \multicolumn{2}{|c|}{ Genome Regions } & $\begin{array}{l}\text { Length } \\
\text { (nt) }\end{array}$ & $\begin{array}{c}\text { Nucleotide } \\
\text { Sequence (nt) }\end{array}$ & $\begin{array}{l}\text { Protein } \\
\text { Size (aa) }\end{array}$ & $\begin{array}{l}\text { Motifs and Domains } \\
\text { (Consensus Sequences) }\end{array}$ & $\begin{array}{l}\text { Nucleotide } \\
\text { Position }\end{array}$ & $\begin{array}{l}\text { Amino Acid } \\
\text { Position }\end{array}$ \\
\hline \multicolumn{2}{|c|}{ Large intergenic region } & 69 & $\begin{array}{c}2162-2196 \\
1-36\end{array}$ & & $\begin{array}{l}\text { Nonanucleotide at the } \\
\text { putative stem-loop } \\
\text { WATAWWHAN }\end{array}$ & $1-9$ & \\
\hline \multirow{7}{*}{$\begin{array}{l}\text { Replicase } \\
\text { (Rep) }\end{array}$} & \multirow{4}{*}{$\begin{array}{l}\text { Catalytic } \\
\text { domain }\end{array}$} & \multirow{4}{*}{668} & \multirow{4}{*}{ 2162-1494 } & \multirow{4}{*}{223} & Motif I [uuTYxQ] & 2073-2090 & $25-30$ \\
\hline & & & & & Motif II $[\mathrm{xHxHx}]$ & 1965-1979 & $62-66$ \\
\hline & & & & & Motif III [YAxK] & $1842-1853$ & $104-107$ \\
\hline & & & & & $\begin{array}{c}\text { GRS domain } \\
{\left[(\mathrm{x})_{2} \mathrm{FD}(\mathrm{x})_{4} \mathrm{HPN}(\mathrm{x})_{5}\right]}\end{array}$ & 1875-1925 & $80-95$ \\
\hline & \multirow{3}{*}{$\begin{array}{l}\text { Central } \\
\text { domain }\end{array}$} & \multirow{3}{*}{375} & \multirow{3}{*}{$1381-1006$} & \multirow{3}{*}{125} & Walker A [G(x) $\left.)_{4} \mathrm{GKT}\right]$ & $1325-1348$ & $7-14$ \\
\hline & & & & & Walker B [xFDDx] & $1220-1234$ & $45-49$ \\
\hline & & & & & Walker C [W/Y $\left.(\mathrm{x})_{2} \mathrm{~N}\right]$ & 1091-1102 & $89-92$ \\
\hline \multicolumn{2}{|c|}{ Capsid (Cap/CP) } & 974 & $36-1010$ & 324 & & & \\
\hline
\end{tabular}

Phylogenetic analysis and pairwise sequence comparison demonstrated that TbGkyV1 shares its highest identity in the Rep protein $(77.5 \%)$ and the complete genome level (nucleotide sequence, 77.2\%) with the "Mongoose associated gemykibivirus 1" (Genbank accession number KP263545) [70] (Figures $3 \mathrm{~B}$ and 6). 

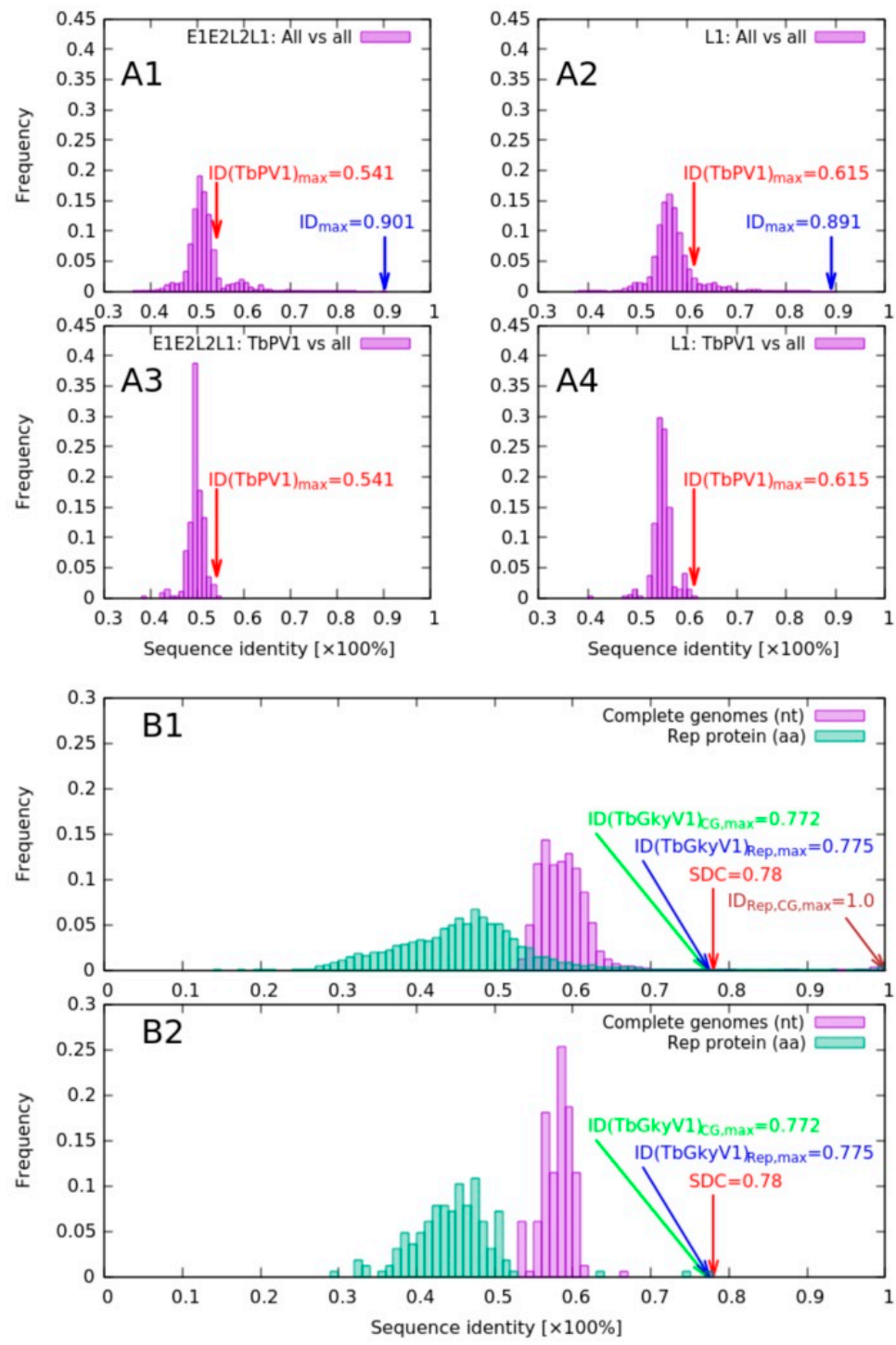

Figure 3. Frequency distribution of pairwise identity values from nucleotide sequence comparisons of PV and genomovirus genome regions. (A) Nucleic sequence identity histograms of the 377 PV nucleotide sequences (A1 and A2) and TbraPV1 (A3 and A4) based on the concatenated E1, E2, L2, and $L 1$ gene sequences (A1 and $\mathrm{A} 3$ ) and on the $L 1$ gene sequence (A2 and A4). Multiple sequence alignments were constructed using Muscle (v3.8.31) [47], and the distance matrices were estimated using SeaView v4.7 [49], as suggested in Bernard et al. (2010). Red arrows indicate the maximum sequence similarities of TbraPV1 for each of the sequence contexts (E1,E2, L2, and L1 concatenation and the $L 1$ gene sequence). The blue arrows (A1 and A2) indicate the overall maximum sequence identity in the depicted context (E1,E2, L2, and L1 concatenation and the L1 gene sequence). The histograms were visualized using gnuplot (v5). (B) Pairwise sequence identity histograms based on 167 complete genome nucleotide (purple) and Rep gene (green) amino acid sequences from the Genomoviridae family, based on the entire pairwise identity distance matrices (B1) and on the matrix slices representing pairwise identities of TbGkyV1 to all other 166 Genomoviridae sequences (B2). The pairwise similarity matrices were obtained through pairwise sequence alignments (Muscle v3.8.31) [47], using Sequence Demarcation Toolkit (SDT v1) [55]. For the arrows in the histogram: red = the species demarcation threshold/criteria (SDC) for Genomoviridae [70]; green and blue = maximum pairwise identity values of TbGkyV1 for the complete genome (green) and the Rep protein sequence contexts (blue). Histograms were visualized using gnuplot (v5). $\mathrm{nt}=$ nucleotide, $\mathrm{aa}=$ amino acid, $\mathrm{SCD}=$ sequence demarcation threshold/criteria [70]. CG: complete genome. 


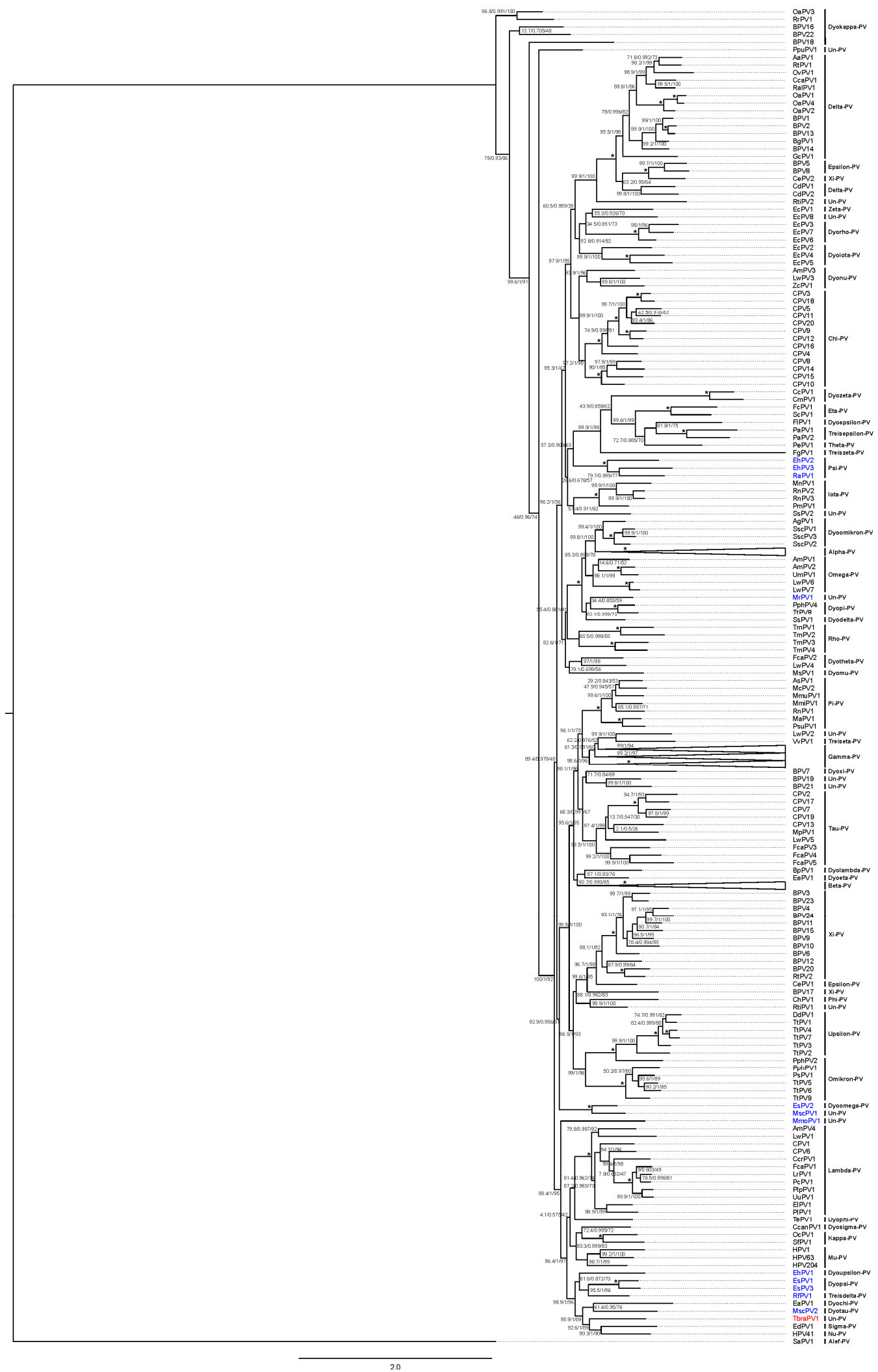

Figure 4. Phylogenetic tree of the PV L1 gene. The tree was constructed using the GTR+F+R10 model, and branches are annotated with SH-aLRT (1000 replicates), aBayes, and UF bootstrap support (1000 replicates) values, respectively. Maximum support values are shown with asterisks $\left(^{*}\right)$. Alpha-, Beta-, and Gamma-PV genera were collapsed. Novel TbraPV1 is depicted in red. Bat PV types are depicted in blue. Un-PV: unclassified PV genera. 


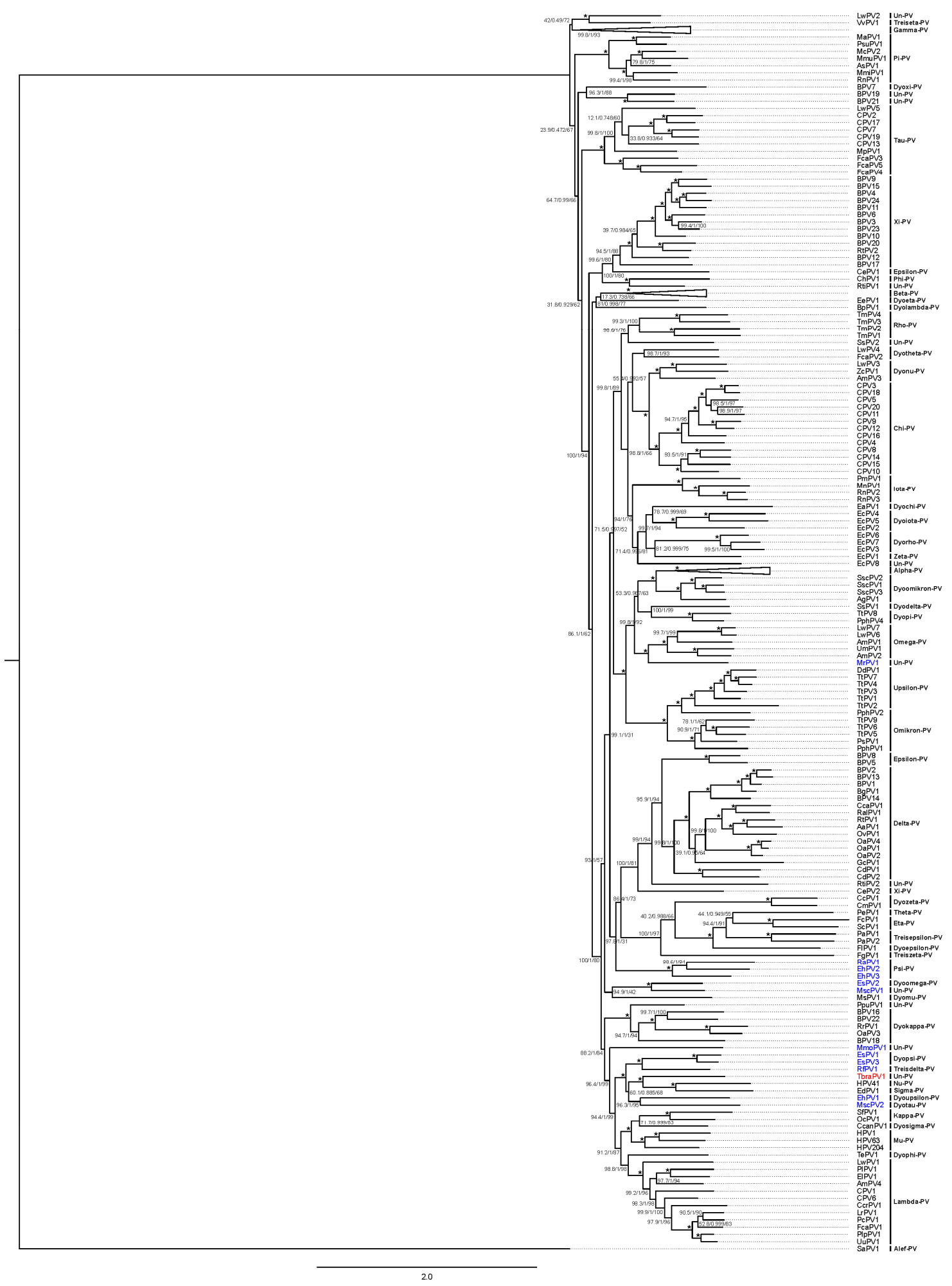

Figure 5. Phylogenetic tree of the concatenated E1,E2, L2, and L1 PV genes. The tree was constructed using the GTR+F+G4 model, and branches are annotated with Sh-aLRT (1000 replicates), aBayes, and UF bootstrap support (1000 replicates) values, respectively. Maximum support values are shown with asterisks $\left(^{*}\right)$. Alpha-, Beta-, and Gamma-PV genera were collapsed. Novel TbraPV1 is depicted in red. Bat PV types are depicted in blue. Un-PV: unclassified PV genera. 


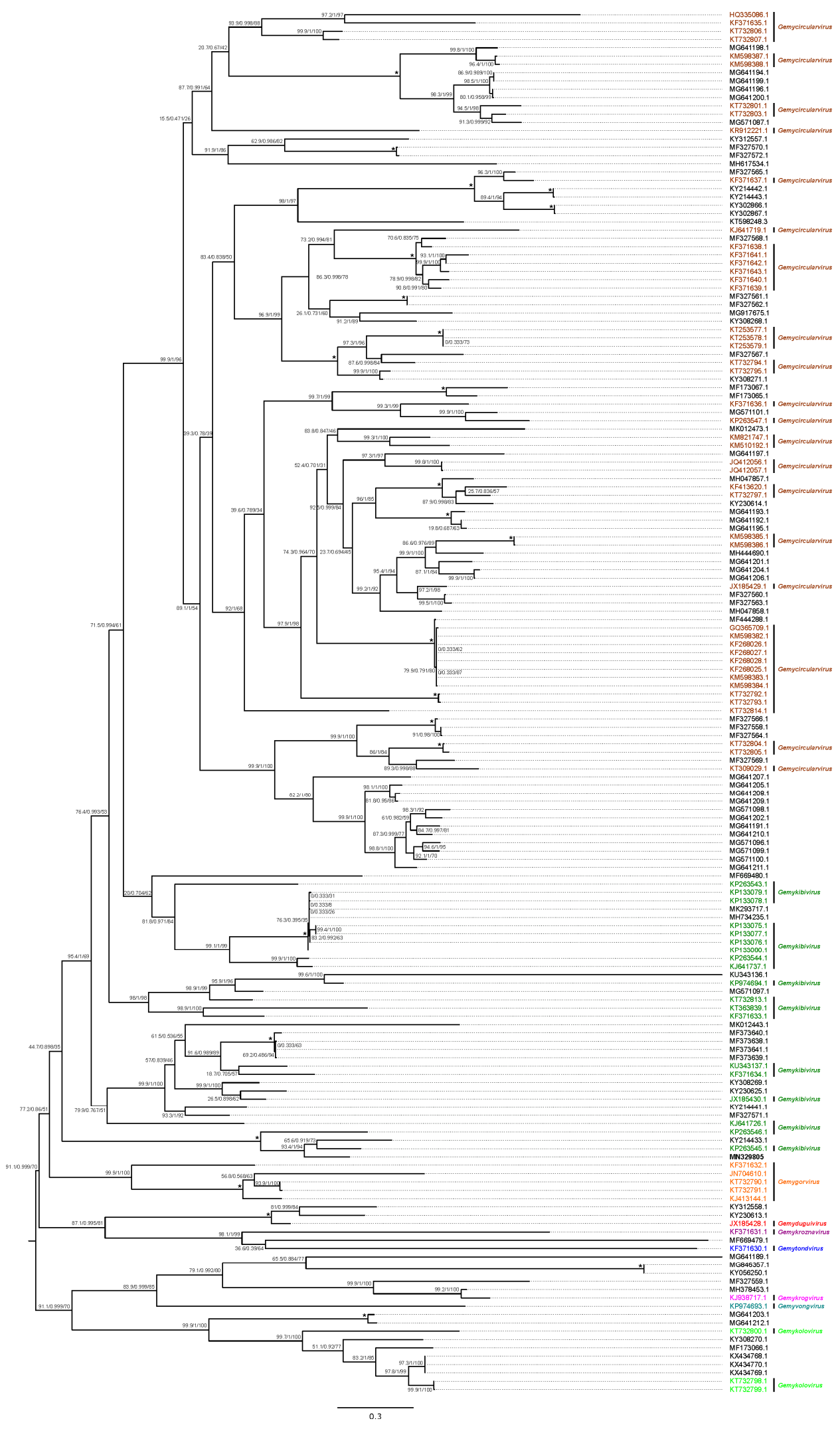

Figure 6. Phylogenetic tree of the Genomovirus Rep amino acid sequence. The tree was constructed using the LG+I+G4 substitution model, and branches are annotated with Sh-aLRT (1000 replicates), aBayes, and UF bootstrap support (1000 replicates) values, respectively. Maximum support values are shown with asterisks $\left({ }^{*}\right)$. Novel TbGkyV1 is depicted in bold. Genomoviridae genera were classified according to Varsani and Krupovic (2017). Unclassified sequences were not depicted. 
Genomic features and conserved domains of the novel gemykibivirus are shown in Table 3 and Figure 2B. The large intergenic region of the novel virus contains the characteristic nonanucleotide (TATAAATAG) motif, which is likely to be important for rolling-circle replication initiation [72-74]. The Rep protein's catalytic domain of TbGkyV1 contained rolling circle replication motif I (LFTYSQ), possibly involved in the recognition of iterative DNA sequences associated with the origin of replication [70], motif II (THLHV), which may regulate the nicking/joining endonuclease activity at the origin of DNA replication [73,75], motif III (YATK), involved in the double-strand DNA cleavage [73,76], and a geminivirus Rep protein sequence (GRS) (RLFDVENFHPNIVPSR), which allows appropriate spatial arrangements of motifs II and III [77]. Furthermore, Rep helicase motifs Walker-A (GPSRTGKT), Walker-B (VFDDI), and Walker-C (WLMN) [78-81] were identified in the central Rep protein domain. Walker motifs contribute to ATP binding, which is used as an energy source to unwind the dsDNA intermediate in the $3^{\prime}-5^{\prime}$ direction by the Rep helicase [80,81].

\section{Discussion}

More than 200 viruses from 27 taxonomic families have been isolated from or detected in bats so far [16], with a few of them implicated in the etiology of several severe diseases in humans. Except for rabies, no direct evidence of zoonotic diseases transmitted by New World bats has been found [27]. New World, especially South American, and Old World bat species had different evolutionary histories, leading to distinct immunological features [3,16]. Viruses infecting South American bat species have been poorly studied [24,26], and further research focused on evaluating their viromes is required. Here, a first attempt to assess to the virome composition in pooled oral and anal swabs of T. brasiliensis was presented.

During our study a total of 6,738,566 read pairs were removed during the laboratory batchbackground screening, due to traces of sequences from co-processed samples. The power of NGS stems from non-specific sampling of nucleic acids and automated repetition, yielding vast numbers of sequencing reads, providing the opportunity to characterize populations of nucleic acids with unprecedented sensitivity, accuracy, and non-specificity. Due to its super-sensitivity, even the slightest addition of environmental nucleic acids to a sample may be detected using NGS and can potentially further complicate the interpretation of the results. Laboratory background and/or DNA isolation kit-derived contamination has been addressed previously as a major factor that can severely impede the interpretation of high throughput sequencing data, and the use of negative controls has been proposed [82]. Moreover, positive/negative control samples have been recommended in metagenomic experiments aimed at detecting pathogens in clinical samples [83]. In this study, the metagenomic sample was processed alongside six samples of molluscum contagiosum skin lesions, and laboratory background filtering was initially considered due to the detection of approximately 90 molluscum contagiosum virus read pairs in the trimmed read dataset. In order to prevent the identification of human skin microflora in the pooled bat swab sample, a strict k-mer based negative filtering was used, effectively removing any read pair that contained at least one $27 \mathrm{bp}$ subsequence that could be identified in any of the read pairs from the six background datasets. Because the background samples also originated from mammalian (human) skin, it could be that a large portion of mammalian reads were removed during this step, explaining the somewhat extreme number of read pairs classified as laboratory-batch background. Moreover, it is also likely that the viral composition of human and bat skin could be shared to some degree, but due to the filtering scheme reads originating from bats' anal and oral microflora sharing nucleotide sequence similarity to that of human skin may have also been removed prior to metagenomic classification. As a consequence, taken strictly, only the subset of viruses that are present in T. brasiliensis, but not in human skin, was explored here. Although DNA spillovers could be suspected and controlled for to some degree, in this case it may be a greater challenge in studies where multiple samples from different species or anatomical sites of bats are processed. In light of the present results, it would likely be beneficial to process the samples in such studies as independently as possible and to include negative controls that would characterize the 
laboratory background, such as sequencing libraries of buffer solutions that underwent the same treatment as the samples, as suggested previously [84,85].

Specifically, a total of 13,897 virus-related read pairs $(0.53 \%$ out of $2,602,700)$ and 153 virus-related contigs $(0.36 \%$ out of 42,891$)$ were assembled de novo, mapped to viral taxa, and identified by NGS. Although the proportion (and number) of virus-related sequences detected in this study $(<1 \%)$ is comparable to reports of previous studies of bat viromes based on Illumina sequencing $[19,21,86]$, it may be that additional physical viral DNA/RNA enrichment steps, such as centrifugation, filtration, and/or nuclease-treatment, could further augment the viral read yields, as suggested previously [87]. Initially, this study was focused on the identification of PVs in T. brasiliensis, in order to explore their diversity in different hosts. Accordingly, swab samples included in this work were first processed using experimental protocols, designed previously to suit our aforementioned initial aim [34-36]. Viral DNA was enriched using RCA, as suggested previously by others [40-42]. However, it should be noted that RCA may have favorably facilitated the amplification of circular genomes and, as a consequence, hindered the detection of linear genomes. Thus, more than $80 \%$ of the classified viral sequences $(11,162 / 13,801)$ identified in our analysis corresponded to circular viral genomes.

In this study about $4.5 \%$ of viral reads and $60 \%$ of contigs corresponded to sequences from 35 eukaryotic viral families, mostly with DNA genomes. Interestingly, virus-associated sequences from RNA viruses belonging to 14 families were also detected, most likely reflecting the presence of traces of viral RNA. Limited but highly accurate reverse transcriptase activity has indeed previously been reported for the phi29 DNA polymerase, used in RCA [88].

Most of the insect-infecting viral sequences detected belonged to viral families infecting lepidopteran adults or larvae, which may represent the diet of $T$. brasiliensis, as detected previously in feces and anal swabs from various insectivorous bat species (Myotis sp., Rhinolophus sp., Molossus sp., Neoromicia sp.), including T. brasiliensis $[19,21,23,26]$. In addition, the detection of various plant viral families in this study could reflect the plant diet of the insects ingested by the bats.

A total of 15 different mammalian viral families were identified in T. brasiliensis samples, representing approximately $43 \%$ (15/35) of the eukaryotic viral families interrogated herein. Several mammalian viral families, supported by the contigs and sequencing reads, have been identified previously in New World $[23,24,26]$ and Old World $[17,18,89]$ bat species. The mammalian viral families identified in T. brasiliensis included typical zoonotic viruses identified previously in bats, such as Polyomaviridae [29], Rhabdoviridae [90], Coronaviridae [23,28], Poxviridae, Flaviviridae, and Adenoviridae [23]. The identification of Circoviridae and Astroviridae in T. brasiliensis was also in line with the results of previous studies [23,31]. On the other hand, this study indicated the presence of Genomoviridae, Alloherpesviridae, Papillomaviridae, Herpesviridae, Paramyxoviridae, and Reoviridae in T. brasiliensis for the first time. Notably, the presence of incorrect annotations in public databases, such as the sequences assigned to the Retroviridae family in this study, highlight the need for the curation of data (whenever possible) to avoid the under- and/or overestimation of the classified sequences derived from metagenomics studies.

PVs are a highly diverse family of non-enveloped and double-stranded circular DNA viruses that are known to infect a wide variety of mammals, as well as birds, reptiles, and fish [91,92]. Various human and non-human PVs, including bat PVs, have frequently been identified in healthy epithelia and may represent part of the native epithelial microflora $[34,57,58]$. Several studies have suggested the presence of PVs in Old World bat species using conventional [57,58,93] or NGS aproches [20,41,94,95]. The only PV type (MmoPV1) identified in a New World bat species (Molossus molossus) has recently been described [26], suggesting a crude sampling imbalance and a severe lack of information to elucidate the evolutionary mechanisms driving PV diversification on the global scale. In this study, TbraPV1 has been identified in pooled oral and anal swabs of T. brasiliensis by NGS, and its sequence has been completely characterized by conventional molecular techniques. TbraPV1 is the first reported PV type found in T. brasiliensis and the second PV type identified in New World bat species. 
According to the current ICTV Papillomaviridae classification guidelines (published in June 2018), based on the nucleotide sequence of the L1 gene [96], TbraPV1 is the founding member of a novel PV genus in the Firstpapillomavirinae taxonomical subfamily, sharing more than $45 \%$ sequence identity to other PV types included in this subfamily. Although nucleotide sequences analysis in the L1 gene indicated that TbraPV1 shares a $61.5 \%$ identity with HPV41 (Nu-PV) and should be included within the same genus (more than $60 \%$ of nucleotide identity in $L 1$ gene) [91], the mentioned demarcation criteria suggests a visual inspection of phylogenetic trees derived from concatenated E1,E2, L1, and L2 nucleotide sequences to delineate PV genera [96]. In the present study, such analysis clustered TbraPV1 basal to the delineation of HPV41 (Nu-PV) and EdPV1 (Sigma-PV), identified in a North American porcupine (Erethizon dorsatum) and, therefore, may represent a novel genus within the Papillomaviridae family. This phylogenetic clustering also indicated that TbraPV1 shares common ancestry with other bat PVs such as EsPV1, EsPV3, RfPV1, EhPV1, and MscPV2. On the other hand, TbraPV1 is only distantly related to RaPV1, EhPV2, EhPV3, EsPV2, MscPV1, and MrPV1, which have been identified from different tissues and bats species. The idea that different bat PVs evolved during a process of strict host coevolution is further refuted by the observation that different bat PVs appear scattered around the Papillomaviridae phylogenetic tree in a highly polyphyletic manner [57,58]. In addition, under strict host coevolution it would be expected for TbraPV1 and MmoPV1, both molossid PVs, to be closely related; nevertheless, MmoPV1 has a basal taxonomic position with respect to TbraPV1. These observations support the idea of multiple evolutionary forces as drivers of PV evolution, including coevolution, adaptive radiation, broad host range, host switch, and recombination [58].

Genomoviruses are single-stranded circular DNA viruses that belong to the recently proposed Genomoviridae family [97]. Members of this family encode two genes-the Cap/CP and the rolling-circle replication-associated protein (Rep) - and an intergenic region. It has been proposed that a novel viral complete genome sequence of the same species exhibits more than $78 \%$ similarity to any other complete genomovirus genome [70]. In addition, in previous studies, the authors aimed to establish nine genera within the family Genomoviridae based on pairwise comparisons of complete genome sequences [70]. CRESS DNA viruses, including genomoviruses, have been found in association with a great variety of animal species, such as camels [98], bats [89], mongooses, badgers [99], wolves [100], pigs [101], and humans [102], as well as in environmental-associated [103] and plant-associated [104] samples. However, no direct implication with a disease has been demonstrated so far. In particular, bat-associated genomoviruses have been identified from feces $[105,106]$ or pharyngeal and anal swab samples [89] of Asiatic [89,105] or European [106] bat species and have been attributed to various taxonomic genera of the Genomoviridae family [70]. TbGkyV1 is a novel species within the Gemykibivirus genus according to the classification criteria [70]. It should be noted that the Rep and Cap proteins of TbGkyV1 exhibited different percentages of similarity, the Cap being considerably more divergent than the Rep, indicating differences in their evolutionary histories due to their respective molecular functions $[70,106]$. To the best of our knowledge, this is the first report demonstrating the presence of genomoviral sequences in mucosal swab samples of a New World bat species.

Finally, it is worth noting that the results of our metagenomic screening of the pooled T. brasiliensis oral and anal swab samples is effectively provided at three different levels of specificity/sensitivity. The two complete genome sequences (TbraPV1 and TbGkyV1), that have been described at the highest level of detail, also confer the highest level of confidence. In other words, we have complete confidence that these two viruses were present in the pooled nucleic acid samples.

Assigning sequences that did not assemble at the level of complete viral genomes to taxonomical families could therefore be a valid approach offering a higher level of sensitivity than only the complete genome assemblies, but at the cost of diminished specificity. In addition, identifying a sequence fragment that resembles a known viral genome in a given genomic region, may not always be sufficient to infer that that specific virus was present in the sample. Viruses are highly promiscuous entities, which can easily exchange parts of their genomes with their hosts, be integrated or even naturalized into the host genomes [107]. Taxonomical viral families identified among the assembled contigs could 
be interpreted as viral families that were probably represented in our samples. Lastly, and due to the low number of assembled contigs, that were found related to known viral sequences, we attempted to increase the sensitivity even further by obtaining taxonomical family mappings also for the source read pairs. These results, however, should be interpreted with utmost caution, because they likely confer a very low level of specificity due to the limited sequence length $(2 \times 150 \mathrm{bp})$. Taxonomical viral families identified by read-pair taxonomy mapping only, merely suggest the possibility that these families were present and should be replicated in the future by taxonomical mappings conferring greater specificity, for example with longer sequences, such as those assembled from Illumina or Nanopore reads.

\section{Conclusions}

This study presents an initial description of the oral/anal virome composition of T. brasiliensis, a widely-distributed New World bat species living in close contact with the human population, for the first time. Although their biological significance is not clear, this work contributes to a better understanding of the evolution and genetic diversity of these viruses. Using conventional nucleic acid detection techniques and/or bioinformatics approaches, the whole genomes of two novel viruses were completely covered, TbraPV1 and TbGkyV1, clustering into the Papillomaviridae and Genomoviridae families. TbraPV1 is the first PV type identified in this host and the prototype of a novel genus in the Firstpapillomavirinae taxonomic subfamily. TbGkyV1 is the first genomovirus reported in New World bats and constitutes a new species within the genus Gemykibivirus. Future studies are required to investigate the possible health impact of the viruses described on bat colonies and to identify the factors that contribute to their dispersal.

Supplementary Materials: The following are available online at http://www.mdpi.com/1999-4915/12/4/422/s1, Supplementary Data 1: Details of the assembled nucleotide sequences obtained by de novo assembly and used in the taxonomic classification as a part of the metagenomic workflow (2) (Figure 1). Table S1: De novo assembly settings in metagenomic workflow: Taxonomic classification of contigs assembled de novo. Post-assembly contig correction was applied in all cases. In the case of Unicycler assembly, the post-assembly contig-correction program was pilon v1.22 [108]. Table S2: List of the 376 reference PV genomes used for the phylogenetic analyses shown in Figures 4 and 5. Details of viral names, abbreviations, host names and GenBank IDs are provided. Nucleotide sequences were downloaded from PaVe (http://pave.niaid.nih.gov/). Table S3: Members of Papillomaviridae and Genomoviridae identified in bat species so far. Details of viruses' taxonomic classification and isolation source as well as host phylogeny and distribution are provided. Table S4: Read pairs and contigs classified as similar to viruses and not taxonomical assigned to viral families identified in anal and oral swab samples of Tadarida brasiliensis obtained by metagenomics using Illumina technology.

Author Contributions: E.M.B.: Conceptualization, Investigation, Writing-Original draft preparation. T.M.Z.: Methodology, Formal analysis, Writing-Original draft preparation. M.E.M.: Resources, Writing-Review and Editing. L.H.: Writing-Review and Editing. D.C.: Conceptualization, Writing-Review and Editing. G.V.: Formal analysis. P.E.C.: Conceptualization, Writing-Review and Editing. R.M.B.: Resources, Writing-Review and Editing. M.P.: Conceptualization, Resources, Writing-Review and Editing. A.A.G.: Conceptualization, Supervision, Resources, Writing-Review and Editing. All authors have read and agreed to the published version of the manuscript.

Funding: This work was funded by: (1) the Bilateral Cooperation Program between Argentina and Slovenia "Development of novel molecular methods for detection and identification of human papillomaviruses from genus Beta and Gamma and their comprehensive molecular-phylogenetic characterization in the oral cavity and nasopharynx" supported by the Ministry of Science, Technology, and Productive Innovation of Argentina (grant agreement no. AR/14/05) and the Slovenian Research Agency (grant agreement nos. P3-0083 and BI-AR/15-17-005), and (2) the European Society of Clinical Microbiology and Infectious Diseases (ESCMID) Observership Program, granted to Elisa M. Bolatti. Elisa M. Bolatti is supported by post-doctoral fellowships of CONICET. The funders had no role in the study design, the data collection and analysis, the preparation of the manuscript, or the decision to publish.

Acknowledgments: The authors thank Irene Villa, German Saigo, Mauricio Taborda, and Violeta Di Domenica for collecting bat samples.

Conflicts of Interest: The authors declare no conflict of interest. 


\section{References}

1. Fenton, N.; Simmons, M. Bats, A World of Science and Mystery., 1st ed.; Univ. Chicago Press. Chicago: Chicago, IL, USA, 2015; p. 330.

2. Simmons, N.B.; Cirranello, A.L. Bat Species of the World: A taxonomic and geographic database. Available online: https://batnames.org/ (accessed on 10 October 2019).

3. Mühldorfer, K.; Speck, S.; Kurth, A.; Lesnik, R.; Freuling, C.; Müller, T.; Kramer-Schadt, S.; Wibbelt, G. Diseases and causes of death in European bats: Dynamics in disease susceptibility and infection rates. PLOS ONE 2011, 6, e29773.

4. Munshi-South, J.; Wilkinson, G.S. Bats and birds: Exceptional longevity despite high metabolic rates. Ageing Res. Rev. 2010, 9, 12-19. [CrossRef] [PubMed]

5. Prendergast, B.J.; Freeman, D.A.; Zucker, I.; Nelson, R.J. Periodic arousal from hibernation is necessary for initiation of immune responses in ground squirrels. Am. J. Physiol. Regul. Integr. Comp. Physiol. 2002, 282, R1054-R1062. [CrossRef] [PubMed]

6. Luis, D.; O'Shea, T.; Hayman, A. A comparison of bats and rodents as reservoirs of zoonotic viruses: Are bats special? Proc. R. Soc. B. 2013, 280, 20122753. [CrossRef] [PubMed]

7. Li, W.; Shi, Z.; Yu, M.; Ren, W.; Smith, C.; Epstein, J.H.; Wang, H.; Crameri, G.; Hu, Z.; Zhang, H.; et al. Bats Are Natural Reservoirs of SARS-Like Coronaviruses. Science 2005, 310, 676-679. [CrossRef] [PubMed]

8. Leroy, E.M.; Kumulungui, B.; Pourrut, X.; Rouquet, P.; Hassanin, A.; Yaba, P.; Délicat, A.; Paweska, J.T.; Gonzalez, J.-P.; Swanepoel, R. Fruit bats as reservoirs of Ebola virus. Nature 2005, 438, 575-576. [CrossRef]

9. Rahman, S.A.; Hassan, S.S.; Olival, K.J.; Mohamed, M.; Chang, L.-Y.; Hassan, L.; Saad, N.M.; Shohaimi, S.A.; Mamat, Z.C.; Naim, M.S.; et al. Characterization of Nipah virus from naturally infected Pteropus vampyrus bats, Malaysia. Emerg. Infect. Dis. 2010, 16, 1990-1993. [CrossRef]

10. Halpin, K.; Young, P.L.; Field, H.E.; Mackenzie, J.S. Isolation of Hendra virus from pteropid bats: A natural reservoir of Hendra virus. J. Gen. Virol 2000, 81, 1927-1932. [CrossRef]

11. Wilkins, K. Tadarida brasiliensis. Mamm. Species 1989, 331, 1-10. [CrossRef]

12. Barquez, R.; Diaz, M.; Gonzalez, E.; Rodriguez, A.; Incháustegui, S.; Arroyo-Cabrales, J. Tadarida brasiliensis. The IUCN Red List of Threatened Species 2015: e.T21314A22121621. Available online: https://dx.doi.org/10.2305/ IUCN.UK.2015-4.RLTS.T21314A22121621.en (accessed on 20 July 2019).

13. Eger, J.L. Family Molossidae. In Mammals of South America. Volume 1. Marsupials, Xenarthrans, Shrews, and Bats; Section Molossidae; Gardner, A.L., Ed.; The University Chicago Press: Chicago, IL, USA, 2007; pp. 399-439.

14. Lewis, M.; Trouwborst, A. Bonn convention on the conservation of migratory species of wild animals 1979. In Elgar Encyclopedia of Environmental Law; Faure, M., Ed.; Edward Elgar Publishing Limited: Cheltenham, UK, 2017; pp. 25-34.

15. Calisher, C.H.; Childs, J.E.; Field, H.E.; Holmes, K.V.; Schountz, T. Bats: Important Reservoir Hosts of Emerging Viruses. Clin. Microbiol. Rev. 2006, 19, 531-545. [CrossRef]

16. Moratelli, R.; Calisher, C.H. Bats and zoonotic viruses: Can we confidently link bats with emerging deadly viruses? Mem. Inst. Oswaldo Cruz 2015, 110, 1-22. [CrossRef] [PubMed]

17. He, B.; Li, Z.; Yang, F.; Zheng, J.; Feng, Y.; Guo, H.; Li, Y.; Wang, Y.; Su, N.; Zhang, F.; et al. Virome profiling of bats from Myanmar by metagenomic analysis of tissue samples reveals more novel Mammalian viruses. PLOS ONE 2013, 8, e61950.

18. Hu, D.; Zhu, C.; Wang, Y.; Ai, L.; Yang, L.; Ye, F.; Ding, C.; Chen, J.; He, B.; Zhu, J.; et al. Virome analysis for identification of novel mammalian viruses in bats from Southeast China. Sci. Rep. 2017, 7, 10917. [CrossRef] [PubMed]

19. Geldenhuys, M.; Mortlock, M.; Weyer, J.; Bezuidt, O.; Seamark, E.C.J.; Kearney, T.; Gleasner, C.; Erkkila, T.H.; Cui, H.; Markotter, W. A metagenomic viral discovery approach identifies potential zoonotic and novel mammalian viruses in Neoromicia bats within South Africa. PLoS ONE 2018, 13, e0194527. [CrossRef] [PubMed]

20. Baker, K.S.; Leggett, R.M.; Bexfield, N.H.; Alston, M.; Daly, G.; Todd, S.; Tachedjian, M.; Holmes, C.E.G.; Crameri, S.; Wang, L.-F.; et al. Metagenomic study of the viruses of African straw-coloured fruit bats: Detection of a chiropteran poxvirus and isolation of a novel adenovirus. Virology 2013, 441, 95-106. [CrossRef] 
21. Dacheux, L.; Cervantes-Gonzalez, M.; Guigon, G.; Thiberge, J.M.; Vandenbogaert, M.; Maufrais, C.; Caro, V.; Bourhy, H. A preliminary study of viral metagenomics of French bat species in contact with humans: Identification of new mammalian viruses. PLoS ONE 2014, 9, e87194. [CrossRef]

22. Kohl, C.; Kurth, A. European bats as carriers of viruses with zoonotic potential. Viruses 2014, 6, 3110-3128. [CrossRef]

23. Li, L.; Victoria, J.G.; Wang, C.; Jones, M.; Fellers, G.M.; Kunz, T.H.; Delwart, E. Bat guano virome: Predominance of dietary viruses from insects and plants plus novel mammalian viruses. J. Virol. 2010, 84, 6955-6965. [CrossRef]

24. Donaldson, E.F.; Haskew, A.N.; Gates, J.E.; Huynh, J.; Moore, C.J.; Frieman, M.B. Metagenomic Analysis of the Viromes of Three North American Bat Species: Viral Diversity among Different Bat Species That Share a Common Habitat. J. Virol. 2010, 84, 13004-13018. [CrossRef]

25. Drexler, J.F.; Corman, V.M.; Müller, M.A.; Maganga, G.D.; Vallo, P.; Binger, T.; Gloza-Rausch, F.; Cottontail, V.M.; Rasche, A.; Yordanov, S.; et al. Bats host major mammalian paramyxoviruses. Nat. Commun. 2012, 3, 796. [CrossRef]

26. Salmier, A.; Tirera, S.; de Thoisy, B.; Franc, A.; Darcissac, E.; Donato, D.; Bouchier, C.; Lacoste, V.; Lavergne, A. Virome analysis of two sympatric bat species (Desmodus rotundus and Molossus molossus) in French Guiana. PLoS ONE 2017, 12, e0186943. [CrossRef] [PubMed]

27. Pinero, C.; Gury Dohmen, F.; Beltran, F.; Martinez, L.; Novaro, L.; Russo, S.; Palacios, G.; Cisterna, D.M. High diversity of rabies viruses associated with insectivorous bats in Argentina: Presence of several independent enzootics. PLoS Negl. Trop. Dis. 2012, 6, e1635. [CrossRef] [PubMed]

28. Simas, P.V.M.; de Souza Barnabé, A.C.; Durães-Carvalho, R.; de Lima Neto, D.F.; Caserta, L.C.; Artacho, L.; Jacomassa, F.A.F.; Martini, M.C.; Bianchi dos Santos, M.M.A.; Felippe, P.A.N.; et al. Bat Coronavirus in Brazil Related to Appalachian Ridge and Porcine Epidemic Diarrhea Viruses. Emerg. Infect. Dis. 2015, 21, 729-731. [CrossRef] [PubMed]

29. De Sales Lima, F.E.; Cibulski, S.P.; Witt, A.A.; Franco, A.C.; Roehe, P.M. Genomic characterization of two novel polyomaviruses in Brazilian insectivorous bats. Arch. Virol. 2015, 160, 1831-1836. [CrossRef]

30. De Sales Lima, F.E.; Cibulski, S.P.; Dos Santos, H.F.; Teixeira, T.F.; Varela, A.P.M.; Roehe, P.M.; Delwart, E.; Franco, A.C. Genomic characterization of novel circular ssDNA viruses from insectivorous bats in Southern Brazil. PLoS ONE 2015, 10, e0118070.

31. Cibulski, S.P.; Teixeira, T.F.; de Sales Lima, F.E.; do Santos, H.F.; Franco, A.C.; Roehe, P.M. A Novel Anelloviridae Species Detected in Tadarida brasiliensis Bats: First Sequence of a Chiropteran Anellovirus. Genome Announc. 2014, 2, e01028-14. [CrossRef]

32. Romano, M.C. Behavior and demography in an urban colony of Tadarida brasiliensis (Chiroptera: Molossidae) in Rosario, Argentina. Rev. Biol. Trop. 1999, 4, 1121-1127.

33. Montani, M.E.; Auil, S.; Duque, C.M.; Romano, M.C.; Cordini, M.C. Estado actual de la colonia de Tadarida brasiliensis (Chiroptera, Molossidae) del SICOM “Facultad de Derecho", Rosario, Argentina. 2015. Available online: http://www.sarem.org.ar/wp-content/uploads/2015/11/SAREM_Resumenes-XXVIII-JAM_2015.pdf (accessed on 1 December 2015).

34. Bolatti, E.M.; Chouhy, D.; Hošnjak, L.; Casal, P.E.; Kocjan, B.J.; Bottai, H.; Stella, E.J.; Sanchez, A.; Bussy, R.F.; Poljak, M.; et al. Natural history of human papillomavirus infection of sun-exposed healthy skin of immunocompetent individuals over three climatic seasons and identification of HPV209, a novel betapapillomavirus. J. Gen. Virol. 2017, 98.

35. Chouhy, D.; Gorosito, M.; Sanchez, A.; Serra, E.C.; Bergero, A.; Fernandez Bussy, R.; Giri, A.A. New generic primer system targeting mucosal/genital and cutaneous human papillomaviruses leads to the characterization of HPV 115, a novel Beta-papillomavirus species 3. Virology 2010, 397, 205-216. [CrossRef]

36. Bolatti, E.M.; Hošnjak, L.; Chouhy, D.; Re-Louhau, M.F.; Casal, P.E.; Bottai, H.; Kocjan, B.J.; Stella, E.J.; Gorosito, M.D.; Sanchez, A.; et al. High prevalence of Gammapapillomaviruses (Gamma-PVs) in pre-malignant cutaneous lesions of immunocompetent individuals using a new broad-spectrum primer system, and identification of HPV210, a novel Gamma-PV type. Virology 2018, 525, 182-191. [CrossRef]

37. Forslund, O.; Antonsson, A.; Nordin, P.; Stenquist, B.; Hansson, B.G. A broad range of human papillomavirus types detected with a general PCR method suitable for analysis of cutaneous tumours and normal skin. J. Gen. Virol. 1999, 80, 2437-2443. [CrossRef] [PubMed] 
38. Forslund, O.; Ly, H.; Reid, C.; Higgins, G. A broad spectrum of human papillomavirus types is present in the skin of Australian patients with non-melanoma skin cancers and solar keratosis. Br. J. Dermatol. 2003, 149, 64-73. [CrossRef] [PubMed]

39. Li, J.; Pan, Y.Q.; Xu, Z.; Wang, Q.; Hang, D.; Shen, N.; Liu, M.; Zhang, C.; Abliz, A.; Deng, Q.; et al. Improved detection of human papillomavirus harbored in healthy skin with FAP6085/64 primers. J. Virol. Methods 2013, 193, 633-638. [CrossRef] [PubMed]

40. Varsani, A.; Kraberger, S.; Jennings, S.; Porzig, E.L.; Julian, L.; Massaro, M.; Pollard, A.; Ballard, G.; Ainley, D.G. A novel papillomavirus in Adélie penguin (Pygoscelis adeliae) faeces sampled at the Cape Crozier colony, Antarctica. J. Gen. Virol. 2014, 95, 1352-1365. [CrossRef] [PubMed]

41. Yinda, C.K.; Rector, A.; Zeller, M.; Conceição-Neto, N.; Heylen, E.; Maes, P.; Ghogomu, S.M.; Van Ranst, M.; Matthijnssens, J. A single bat species in Cameroon harbors multiple highly divergent papillomaviruses in stool identified by metagenomics analysis. Virol. Reports 2016, 6, 74-80. [CrossRef]

42. Van Doorslaer, K.; Ruoppolo, V.; Schmidt, A.; Lescroël, A.; Jongsomjit, D.; Elrod, M.; Kraberger, S.; Stainton, D.; Dugger, K.M.; Ballard, G.; et al. Unique genome organization of non-mammalian papillomaviruses provides insights into the evolution of viral early proteins. Virus Evol. 2017, 3, 1-12. [CrossRef]

43. Kim, D.; Song, L.; Breitwieser, F.P.; Salzberg, S.L. Centrifuge: Rapid and sensitive classification of metagenomic sequences. Genome Res. 2016, 26, 1721-1729. [CrossRef]

44. Breitwieser, F.P.; Salzberg, S.L. Pavian: Interactive analysis of metagenomics data for microbiome studies and pathogen identification. Bioinformatics 2020, 36, 1303-1304. [CrossRef]

45. Bankevich, A.; Nurk, S.; Antipov, D.; Gurevich, A.A.; Dvorkin, M.; Kulikov, A.S.; Lesin, V.M.; Nikolenko, S.I.; Pham, S.; Prjibelski, A.D.; et al. SPAdes: A new genome assembly algorithm and its applications to single-cell sequencing. J. Comput. Biol. 2012, 19, 455-477. [CrossRef]

46. Langmead, B.; Salzberg, S.L. Fast gapped-read alignment with Bowtie 2. Nat. Methods 2012, 9, 357-359. [CrossRef]

47. Edgar, R.C. MUSCLE: A multiple sequence alignment method with reduced time and space complexity. BMC Bioinformatics 2004, 5, 113. [CrossRef] [PubMed]

48. Bernard, H.U.; Burk, R.D.; Chen, Z.; van Doorslaer, K.; Hausen, H.Z.; de Villiers, E.M. Classification of papillomaviruses (PVs) based on 189 PV types and proposal of taxonomic amendments. Virology 2010, 401, 70-79. [CrossRef] [PubMed]

49. Gouy, M.; Guindon, S.; Gascuel, O. SeaView Version 4: A Multiplatform Graphical User Interface for Sequence Alignment and Phylogenetic Tree Building. Mol. Biol. Evol. 2010, 27, 221-224. [CrossRef] [PubMed]

50. Nguyen, L.-T.; Schmidt, H.A.; von Haeseler, A.; Minh, B.Q. IQ-TREE: A fast and effective stochastic algorithm for estimating maximum-likelihood phylogenies. Mol. Biol. Evol. 2015, 32, 268-274. [CrossRef] [PubMed]

51. Kalyaanamoorthy, S.; Minh, B.Q.; Wong, T.K.F.; von Haeseler, A.; Jermiin, L.S. ModelFinder: Fast model selection for accurate phylogenetic estimates. Nat. Methods 2017, 14, 587-589. [CrossRef] [PubMed]

52. Hoang, D.T.; Chernomor, O.; von Haeseler, A.; Minh, B.Q.; Vinh, L.S. UFBoot2: Improving the Ultrafast Bootstrap Approximation. Mol. Biol. Evol. 2018, 35, 518-522. [CrossRef]

53. Anisimova, M.; Gil, M.; Dufayard, J.-F.; Dessimoz, C.; Gascuel, O. Survey of branch support methods demonstrates accuracy, power, and robustness of fast likelihood-based approximation schemes. Syst. Biol. 2011, 60, 685-699. [CrossRef]

54. Hunt, M.; De Silva, N.; Otto, T.D.; Parkhill, J.; Keane, J.A.; Harris, S.R. Circlator: Automated circularization of genome assemblies using long sequencing reads. Genome Biol. 2015, 16, 294. [CrossRef]

55. Muhire, B.M.; Varsani, A.; Martin, D.P. SDT: A virus classification tool based on pairwise sequence alignment and identity calculation. PLOS ONE 2014, 9, e108277.

56. Escalera-Zamudio, M.; Mendoza, M.L.Z.; Heeger, F.; Loza-Rubio, E.; Rojas-Anaya, E.; Méndez-Ojeda, M.L.; Taboada, B.; Mazzoni, C.J.; Arias, C.F.; Greenwood, A.D. A Novel Endogenous Betaretrovirus in the Common Vampire Bat (Desmodus rotundus) Suggests Multiple Independent Infection and Cross-Species Transmission Events. J. Virol. 2015, 89, 5180-5184. [CrossRef]

57. Garcia-Perez, R.; Gottschling, M.; Wibbelt, G.; Bravo, I.G. Multiple evolutionary origins of bat papillomaviruses. Vet. Microbiol 2013, 165, 51-60. [CrossRef] [PubMed]

58. García-Pérez, R.; Ibáñez, C.; Godínez, J.M.; Aréchiga, N.; Garin, I.; Pérez-Suárez, G.; De Paz, O.; Juste, J.; Echevarría, J.E.; Bravo, I.G. Novel papillomaviruses in free-ranging Iberian bats: No virus-host co-evolution, no strict host specificity, and hints for recombination. Genome Biol. Evol. 2014, 6, 94-104. [CrossRef] [PubMed] 
59. Doorbar, J. The E4 protein; structure, function and patterns of expression. Virology 2013, 445, 80-98. [CrossRef]

60. Oštrbenk, A.; Kocjan, B.J.; Hošnjak, L.; Li, J.; Deng, Q.; Šterbenc, A.; Poljak, M. Identification of a Novel Human Papillomavirus, Type HPV199, Isolated from a Nasopharynx and Anal Canal, and Complete Genomic Characterization of Papillomavirus Species Gamma-12. PLoS ONE 2015, 16. [CrossRef] [PubMed]

61. Ullman, C.G.; Haris, P.I.; Galloway, D.A.; Emery, V.C.; Perkins, S.J. Predicted alpha-helix/beta-sheet secondary structures for the zinc-binding motifs of human papillomavirus E7 and E6 proteins by consensus prediction averaging and spectroscopic studies of E7. Biochem J. 1996, 319, 229-239. [CrossRef] [PubMed]

62. Fanning, A.S.; Anderson, J.M. PDZ domains: Fundamental building blocks in the organization of protein complexes at the plasma membrane. J. Clin. Invest. 1999, 103, 767-772. [CrossRef] [PubMed]

63. Radulescu, R.T.; Bellitti, M.R.; Ruvo, M.; Cassani, G.; Fassina, G. Binding of the LXCXE insulin motif to a hexapeptide derived from retinoblastoma protein. Biochem. Biophys. Res. Commun. 1995, 206, 97-102. [CrossRef]

64. Titolo, S.; Pelletier, A.; Sauve, F.; Brault, K.; Wardrop, E.; White, P.W.; Amin, A.; Cordingley, M.G.; Archambault, J. Role of the ATP-binding domain of the human papillomavirus type 11 E1 helicase in E2-dependent binding to the origin. J. Virol. 1999, 73, 5282-5293. [CrossRef]

65. Mantovani, F.; Banks, L. The human papillomavirus E6 protein and its contribution to malignant progression. Oncogene 2001, 20, 7874-7887. [CrossRef]

66. Lange, A.; Mills, R.E.; Lange, C.J.; Stewart, M.; Devine, S.E.; Corbett, A.H. Classical nuclear localization signals: Definition, function, and interaction with importin alpha. J. Biol. Chem. 2007, 282, 5101-5105. [CrossRef]

67. Fradet-Turcotte, A.; Moody, C.; Laimins, L.A.; Archambault, J. Nuclear export of human papillomavirus type $31 \mathrm{E} 1$ is regulated by Cdk2 phosphorylation and required for viral genome maintenance. J. Virol. 2010, 84, 11747-11760. [CrossRef] [PubMed]

68. Wang, J.W.; Roden, R.B. L2, the minor capsid protein of papillomavirus. Virology 2013, 445, 175-186. [CrossRef]

69. Johansson, C.; Schwartz, S. Regulation of human papillomavirus gene expression by splicing and polyadenylation. Nat. Rev. Microbiol. 2013, 11, 239-251. [CrossRef] [PubMed]

70. Varsani, A.; Krupovic, M. Sequence-based taxonomic framework for the classification of uncultured single-stranded DNA viruses of the family Genomoviridae. Virus Evol. 2017, 3, vew037. [CrossRef] [PubMed]

71. Zhao, L.; Rosario, K.; Breitbart, M.; Duffy, S. Eukaryotic Circular Rep-Encoding Single-Stranded DNA (CRESS DNA) Viruses: Ubiquitous Viruses With Small Genomes and a Diverse Host Range. In Advances in Virus Research; Academic Press Inc: Cambridge, MA, USA, 2019; Volume 103, pp. 71-133. ISBN 9780128177228.

72. Heyraud-Nitschke, F.; Schumacher, S.; Laufs, J.; Schaefer, S.; Schell, J.; Gronenborn, B. Determination of the origin cleavage and joining domain of geminivirus Rep proteins. Nucleic Acids Res. 1995, 23, 910-916. [CrossRef] [PubMed]

73. Laufs, J.; Schumacher, S.; Geisler, N.; Jupin, I.; Gronenborn, B. Identification of the nicking tyrosine of geminivirus Rep protein. FEBS Lett. 1995, 377, 258-262. [CrossRef]

74. Timchenko, T.; de Kouchkovsky, F.; Katul, L.; David, C.; Vetten, H.J.; Gronenborn, B. A single rep protein initiates replication of multiple genome components of faba bean necrotic yellows virus, a single-stranded DNA virus of plants. J. Virol. 1999, 73, 10173-10182. [CrossRef]

75. Koonin, E.V.; Ilyina, T. V Geminivirus replication proteins are related to prokaryotic plasmid rolling circle DNA replication initiator proteins. J. Gen. Virol. 1992, 73, 2763-2766. [CrossRef]

76. Orozco, B.M.; Hanley-Bowdoin, L. Conserved sequence and structural motifs contribute to the DNA binding and cleavage activities of a geminivirus replication protein. J. Biol. Chem. 1998, 273, 24448-24456. [CrossRef]

77. Nash, T.E.; Dallas, M.B.; Reyes, M.I.; Buhrman, G.K.; Ascencio-Ibañez, J.T.; Hanley-Bowdoin, L. Functional analysis of a novel motif conserved across geminivirus Rep proteins. J. Virol. 2011, 85, 1182-1192. [CrossRef]

78. Gorbalenya, A.E.; Koonin, E.V.; Wolf, Y.I. A new superfamily of putative NTP-binding domains encoded by genomes of small DNA and RNA viruses. FEBS Lett. 1990, 262, 145-148. [CrossRef]

79. Koonin, E.V. A common set of conserved motifs in a vast variety of putative nucleic acid-dependent ATPases including MCM proteins involved in the initiation of eukaryotic DNA replication. Nucleic Acids Res. 1993, 21, 2541-2547. [CrossRef] [PubMed]

80. Choudhury, N.R.; Malik, P.S.; Singh, D.K.; Islam, M.N.; Kaliappan, K.; Mukherjee, S.K. The oligomeric Rep protein of Mungbean yellow mosaic India virus (MYMIV) is a likely replicative helicase. Nucleic Acids Res. 2006, 34, 6362-6377. [CrossRef] [PubMed] 
81. Clerot, D.; Bernardi, F. DNA Helicase Activity Is Associated with the Replication Initiator Protein Rep of Tomato Yellow Leaf Curl Geminivirus. J. Virol. 2006, 80, 11322-11330. [CrossRef]

82. Asplund, M.; Kjartansdóttir, K.R.; Mollerup, S.; Vinner, L.; Fridholm, H.; Herrera, J.A.R.; Friis-Nielsen, J.; Hansen, T.A.; Jensen, R.H.; Nielsen, I.B.; et al. Contaminating viral sequences in high-throughput sequencing viromics: A linkage study of 700 sequencing libraries. Clin. Microbiol. Infect. 2019, 25, 1277-1285. [CrossRef]

83. Gu, W.; Miller, S.; Chiu, C.Y. Clinical Metagenomic Next-Generation Sequencing for Pathogen Detection. Annu. Rev. Pathol. Mech. Dis. 2019, 14,319-338. [CrossRef]

84. Simner, P.J.; Miller, H.B.; Breitwieser, F.P.; Pinilla Monsalve, G.; Pardo, C.A.; Salzberg, S.L.; Sears, C.L.; Thomas, D.L.; Eberhart, C.G.; Carroll, K.C. Development and Optimization of Metagenomic Next-Generation Sequencing Methods for Cerebrospinal Fluid Diagnostics. J. Clin. Microbiol. 2018, 56, e00472-18. [CrossRef]

85. Bal, A.; Pichon, M.; Picard, C.; Casalegno, J.S.; Valette, M.; Schuffenecker, I.; Billard, L.; Vallet, S.; Vilchez, G.; Cheynet, V.; et al. Quality control implementation for universal characterization of DNA and RNA viruses in clinical respiratory samples using single metagenomic next-generation sequencing workflow. BMC Infect. Dis. 2018, 18, 537. [CrossRef]

86. Ge, X.; Li, Y.; Yang, X.; Zhang, H.; Zhou, P.; Zhang, Y.; Shi, Z. Metagenomic Analysis of Viruses from Bat Fecal Samples Reveals Many Novel Viruses in Insectivorous Bats in China. J. Virol. 2012, 86, 4620-4630. [CrossRef]

87. Hall, R.J.; Wang, J.; Todd, A.K.; Bissielo, A.B.; Yen, S.; Strydom, H.; Moore, N.E.; Ren, X.; Huang, Q.S.; Carter, P.E.; et al. Evaluation of rapid and simple techniques for the enrichment of viruses prior to metagenomic virus discovery. J. Virol. Methods 2014, 195, 194-204. [CrossRef]

88. Krzywkowski, T.; Kühnemund, M.; Wu, D.; Nilsson, M. Limited reverse transcriptase activity of phi29 DNA polymerase. Nucleic Acids Res. 2018, 46, 3625-3632. [CrossRef] [PubMed]

89. Wu, Z.; Yang, L.; Ren, X.; He, G.; Zhang, J.; Yang, J.; Qian, Z.; Dong, J.; Sun, L.; Zhu, Y.; et al. Deciphering the bat virome catalog to better understand the ecological diversity of bat viruses and the bat origin of emerging infectious diseases. ISME J. 2016, 10, 609-620. [CrossRef] [PubMed]

90. Piñero, C.; Dohmen, F.; Beltran, F.; Martinez, L.; Novaro, L.; Russo, S.; Palacios, G.; Cisterna, D.M. High diversity of rabies viruses associated with insectivorous bats in Argentina: Presence of several independent enzootics. PLoS Negl. Trop. Dis. 2012, 6, e1635. [CrossRef]

91. De Villiers, E.M.; Fauquet, C.; Broker, T.R.; Bernard, H.U.; zur Hausen, H. Classification of papillomaviruses. Virology 2004, 324, 17-27. [CrossRef] [PubMed]

92. Bravo, I.G.; de Sanjosé, S.; Gottschling, M. The clinical importance of understanding the evolution of papillomaviruses. Trends Microbiol. 2010, 18, 432-438. [CrossRef]

93. Rector, A.; Mostmans, S.; Van Doorslaer, K.; McKnight, C.A.; Maes, R.K.; Wise, A.G.; Kiupel, M.; Van Ranst, M. Genetic characterization of the first chiropteran papillomavirus, isolated from a basosquamous carcinoma in an Egyptian fruit bat: The Rousettus aegyptiacus papillomavirus type 1. Vet. Microbiol 2006, 117, 267-275. [CrossRef] [PubMed]

94. Zheng, X.Y.; Qiu, M.; Guan, W.J.; Li, J.M.; Chen, S.W.; Cheng, M.J.; Huo, S.T.; Chen, Z.; Wu, Y.; Jiang, L.N.; et al. Viral metagenomics of six bat species in close contact with humans in southern China. Arch. Virol. 2018, 163, 73-88. [CrossRef] [PubMed]

95. Tse, H.; Tsang, A.K.; Tsoi, H.W.; Leung, A.S.; Ho, C.C.; Lau, S.K.; Woo, P.C.; Yuen, K.Y. Identification of a novel bat papillomavirus by metagenomics. PLoS ONE 2012, 7, e43986. [CrossRef] [PubMed]

96. Van Doorslaer, K.; Chen, Z.; Bernard, H.U.; Chan, P.K.S.; Desalle, R.; Dillner, J.; Forslund, O.; Haga, T.; McBride, A.A.; Villa, L.L.; et al. ICTV virus taxonomy profile: Papillomaviridae. J. Gen. Virol. 2018, 99, 989-990. [CrossRef]

97. Krupovic, M.; Ghabrial, S.A.; Jiang, D.; Varsani, A. Genomoviridae: A new family of widespread single-stranded DNA viruses. Arch. Virol. 2016, 161, 2633-2643. [CrossRef]

98. Li, Y.; Khalafalla, A.I.; Paden, C.R.; Yusof, M.F.; Eltahir, Y.M.; Al Hammadi, Z.M.; Tao, Y.; Queen, K.; Al Hosani, F.; Gerber, S.I.; et al. Identification of diverse viruses in upper respiratory samples in dromedary camels from United Arab Emirates. PLoS ONE 2017, 12, e0184718. [CrossRef] [PubMed]

99. Conceição-Neto, N.; Zeller, M.; Heylen, E.; Lefrère, H.; Mesquita, J.R.; Matthijnssens, J. Fecal virome analysis of three carnivores reveals a novel nodavirus and multiple gemycircularviruses. Virol. J. 2015, 12, 79. [CrossRef] [PubMed] 
100. Conceição-Neto, N.; Theuns, S.; Cui, T.; Zeller, M.; Yinda, C.K.; Christiaens, I.; Heylen, E.; Van Ranst, M.; Carpentier, S.; Nauwynck, H.J.; et al. Identification of an enterovirus recombinant with a torovirus-like gene insertion during a diarrhea outbreak in fattening pigs. Virus Evol. 2017, 3, 1-11. [CrossRef] [PubMed]

101. Conceição-Neto, N.; Godinho, R.; Álvares, F.; Yinda, C.K.; Deboutte, W.; Zeller, M.; Laenen, L.; Heylen, E.; Roque, S.; Petrucci-Fonseca, F.; et al. Viral gut metagenomics of sympatric wild and domestic canids, and monitoring of viruses: Insights from an endangered wolf population. Ecol. Evol. 2017, 7, 4135-4146. [CrossRef]

102. Phan, T.G.; Mori, D.; Deng, X.; Rajindrajith, S.; Ranawaka, U.; Fan Ng, T.F.; Bucardo-Rivera, F.; Orlandi, P.; Ahmed, K.; Delwart, E. Small circular single stranded DNA viral genomes in unexplained cases of human encephalitis, diarrhea, and in untreated sewage. Virology 2015, 482, 98-104. [CrossRef]

103. Da Silva Assis, M.R.; Vieira, C.B.; Fioretti, J.M.; Rocha, M.S.; de Almeida, P.I.N.; Miagostovich, M.P.; Fumian, T.M. Detection and Molecular Characterization of Gemycircularvirus from Environmental Samples in Brazil. Food Environ. Virol. 2016, 8, 305-309. [CrossRef]

104. Du, Z.; Tang, Y.; Zhang, S.; She, X.; Lan, G.; Varsani, A.; He, Z. Identification and molecular characterization of a single-stranded circular DNA virus with similarities to Sclerotinia sclerotiorum hypovirulence-associated DNA virus 1. Arch. Virol. 2014, 159, 1527-1531. [CrossRef]

105. Male, M.F.; Kami, V.; Kraberger, S.; Varsani, A. Genome Sequences of Poaceae-Associated Gemycircularviruses from the Pacific Ocean Island of Tonga. Genome Announc. 2015, 3, e01144. [CrossRef]

106. Kemenesi, G.; Kurucz, K.; Zana, B.; Földes, F.; Urbán, P.; Vlaschenko, A.; Kravchenko, K.; Budinski, I.; Szodoray-Parádi, F.; Bücs, S.; et al. Diverse replication-associated protein encoding circular DNA viruses in guano samples of Central-Eastern European bats. Arch. Virol. 2018, 163, 671-678. [CrossRef]

107. Koonin, E.V.; Dolja, V.V.; Krupovic, M.; Varsani, A.; Wolf, Y.I.; Yutin, N.; Zerbini, F.M.; Kuhn, J.H. Global Organization and Proposed Megataxonomy of the Virus World. Microbiol. Mol. Biol. Rev. 2020, 84, 1-33. [CrossRef]

108. Walker, B.J.; Abeel, T.; Shea, T.; Priest, M.; Abouelliel, A.; Sakthikumar, S.; Cuomo, C.A.; Zeng, Q.; Wortman, J.; Young, S.K.; et al. Pilon: An integrated tool for comprehensive microbial variant detection and genome assembly improvement. PLoS ONE 2014, 9, e112963. [CrossRef] [PubMed]

(C) 2020 by the authors. Licensee MDPI, Basel, Switzerland. This article is an open access article distributed under the terms and conditions of the Creative Commons Attribution (CC BY) license (http://creativecommons.org/licenses/by/4.0/). 